\title{
Glass Binder Development for a Glass-Bonded Sodalite Ceramic Waste Form
}

\author{
Brian J. Riley, ${ }^{* \dagger}$ John D. Vienna, ${ }^{\dagger}$ Steven M. Frank, ${ }^{\dagger}$ Jared O. Kroll, ${ }^{\dagger}$ Jacob A. Peterson, ${ }^{\dagger}$ Nathan L. \\ Canfield, ${ }^{\dagger}$ Zihua Zhu, ${ }^{\dagger}$ Jiandong Zhang, ${ }^{\dagger}$ Karen Kruska, ${ }^{\dagger}$ Daniel K. Schreiber, ${ }^{\dagger}$ and Jarrod V. Crum ${ }^{\dagger}$ \\ ${ }^{\dagger}$ Pacific Northwest National Laboratory, Richland, WA 99354, United States \\ Idaho National Laboratory, Idaho Falls, ID 83402, United States
}

\begin{abstract}
This paper discusses work to develop $\mathrm{Na}_{2} \mathrm{O}-\mathrm{B}_{2} \mathrm{O}_{3}-\mathrm{SiO}_{2}$ glass binders for immobilizing $\mathrm{LiCl}-\mathrm{KCl}$ eutectic salt waste in a glass-bonded sodalite waste form following electrochemical reprocessing of used metallic nuclear fuel. Here, five new glasses with $\sim 20$ mass $\% \mathrm{Na}_{2} \mathrm{O}$ were designed to generate waste forms with high sodalite. The glasses were then used to produce ceramic waste forms with a surrogate salt waste. The waste forms made using these new glasses were formulated to generate more sodalite than those made with previous baseline glasses for this type of waste. The coefficients of thermal expansion for the glass phase in the glass-bonded sodalite waste forms made with the new binder glasses were closer to the sodalite phase in the critical temperature region near and below the glass transition temperature than previous binder glasses used. These improvements should result in lower probability of cracking in the full-scale monolithic ceramic waste form, leading to better long-term chemical durability.
\end{abstract}

\section{Introduction}

Electrochemical reprocessing of used nuclear fuel is a viable option for separating fissionable actinides from the fission products generated in a nuclear reactor. For Experimental Breeder Reactor (EBR-II) fuel, a LiCl-KCl (ER) eutectic salt is used to dissolve the fuel within an electrorefiner [1]. An oxidant (i.e., $\mathrm{CdCl}_{2}$ or $\mathrm{UCl}_{3}$ ) is added to assist with redox reactions where the active metal fission products, the $\mathrm{Na}^{0}$ (used as a thermal bond between the fuel and the cladding), as well as the $\mathrm{U}, \mathrm{Pu}$, and minor actinides form chlorides. Uranium is then reduced to $\mathrm{U}^{0}$ at the cathode and harvested. A LiCl-KCl

\footnotetext{
*Corresponding author: Brian J. Riley, brian.riley@pnnl.gov, (509)372-4651 (phone), (509)372-5997 (fax)
} 
binary phase diagram $[2,3]$ with a few added data points with various loadings of $\mathrm{UCl}_{3}[4]$ is presented in Figure 1 for reference.

Over time, a number of factors may require that salt be removed from the electrorefiner for disposal. Researchers at Argonne National Laboratory anticipated the need to treat waste ER salt for disposal and developed a durable ceramic waste form (CWF) to immobilize the salt and fission products [5]. To treat waste ER salt, the salt is mixed with zeolite $4 \mathrm{~A}$ under high temperatures $\left(\sim 500{ }^{\circ} \mathrm{C}\right)$ to occlude the salt into the zeolite matrix. The salt-occluded zeolite (SOZ) is then mixed with a glass binder (25 mass $\%$ ) and heated to form a dense monolithic waste form with an overall salt loading of $\sim 8$ mass $\%$. During heat treatment, the SOZ transforms to sodalite $\left[\mathrm{Na}_{8}\left(\mathrm{AlSiO}_{4}\right)_{6} \mathrm{Cl}_{2}\right]$ and the glass binder encapsulates the sodalite, often referred to as a glass-bonded sodalite waste form. Early in the developmental stages of the CWF, the mixed SOZ and glass binder were processed using a hot isostatic press; however, for full-scale processing, a pressureless consolidation method was developed to ease operational constraints [6]. This concept of a glass-bonded mineral waste form, also referred to as a glass composite material, has been demonstrated a lot in the literature for various wastes including clinoptilolite $\left[(\mathrm{Na}, \mathrm{K}, \mathrm{Ca})_{2-3} \mathrm{Al}_{3}(\mathrm{Al}, \mathrm{Si})_{2} \mathrm{Si}_{13} \mathrm{O}_{36} \cdot 12 \mathrm{H}_{2} \mathrm{O}\right]$ [7-9] in addition to sodalite [10-14] and apatite $\left[\mathrm{Ca}_{5}\left(\mathrm{PO}_{4}\right)_{3} \mathrm{Cl}\right]$ [14-16].

In the $\mathrm{CWF}$, the $\mathrm{Cl}$ and $\mathrm{I}$ as well as some of the alkali metals are incorporated in sodalite, whereas the actinides and rare earths are either incorporated in the glass phase or form separate mixed-oxide [17, 18], silicate [19, 20], and/or aluminosilicate [19] inclusions in the glass. Other constituents in the waste salt including the other alkali, alkaline earth, and transition metals incorporate into the glass. This all occurs through ion exchange between the SOZ and glass binder during heat-treatment. In most cases, alkali chlorides are found within heat-treated samples near the actinide and rare earth oxide phases due to trace residual moisture in the zeolite $[18,20]$. The fates of the alkalis (e.g., Li, Na, K, Cs) are different, where the Na preferentially incorporates into the sodalite, and some of the others (e.g., Li, K, Cs) tend to preferentially concentrate in the glass phase [6]. The goal of the CWF process is to incorporate the halides from the waste salt into sodalite through the reaction shown in Equation (1) between $\mathrm{NaCl}$ and zeolite 4A. 
However, very little $\mathrm{NaCl}$ is present in the salt. Thus, in order to accommodate the maximum amount of halides in the sodalite and optimize waste loading in the CWF, additional $\mathrm{Na}$ is required from the glass for optimal sodalite production. It is unclear if this preference for $\mathrm{Na}$ is based on the crystal radius of the various alkalis, where $\mathrm{Li}_{I V}^{+}=73 \mathrm{pm}, \mathrm{Na}_{I V}^{+}=113 \mathrm{pm}, \mathrm{K}_{I V}^{+}=151 \mathrm{pm}$, and $\mathrm{Cs}_{V I}^{+}=181 \mathrm{pm}$ (subscript numeral is the coordination number) [21].

$$
4 \mathrm{NaCl}+\mathrm{Na}_{12}\left(\mathrm{AlSiO}_{4}\right)_{12} \rightarrow 2 \mathrm{Na}_{8}\left(\mathrm{AlSiO}_{4}\right)_{6} \mathrm{Cl}_{2}
$$

The primary goal of the current work was to develop a glass binder optimized for the glassbonded sodalite immobilization concept, aiming to meet most (if not all) of the criteria presented by Bateman et al. [22] (discussed in section 2). In the current work, five new glass binders (i.e., NBS-2, NBS-3, NBS-4, NBS-5, and NBS-6) were used to make waste forms with higher salt loadings (10-14 mass \%) than previously used ( $\sim$ mass \%) [23]. Waste forms with higher salt loadings were also made with the previously tested binder glass (Pemco-57 or P57) for comparison. Additionally, the CWF process was evaluated with NBS-4 at the $11 \%$ salt loading while using smaller starting reactant particle sizes as well as with the standard-sized particles at an alternate glass loading (40 mass \%).

The work presented here includes the selection process behind the new glass binder compositions, a summary of the CWF production process used to make each sample, characterization of the CWFs made with the new binders (called Advanced CWFs, or ACWFs), and a predictive softening temperature $\left(T_{\mathrm{s}}\right)$ model for silicate glasses. A variety of characterization techniques were employed for characterization of the glass binders as well as the CWFs and ACWFs, including dilatometry, scanning electron microscopy (SEM), energy dispersive spectroscopy (EDS), hot-stage (HS-) and powder (P-) Xray diffraction (XRD), time-of-flight secondary ion mass spectrometry (ToF-SIMS), atom probe tomography (APT), Archimedes' approach for measuring porosity and density, specific surface area using $\mathrm{Kr}$ gas, and He gas pycnometry. 


\section{Glass binder formulation}

Bateman et al. [22] summarized the optimal glass properties for achieving an acceptable CWF product as well as a brief history of the down-selection process for choosing a binder glass, and some of that will be summarized here. According to Bateman et al., the ideal binder glass should: 1) have a glass softening temperature $\left(T_{\mathrm{s}}\right)$ that is $<750{ }^{\circ} \mathrm{C}$, where ideal processing temperatures are in the range of 750 $925^{\circ} \mathrm{C}, 2$ ) have a long working range so it does not drain through the product during heat-treatment, 3 ) wet the SOZ/sodalite mixture, 4) have a coefficient of thermal expansion (CTE) that is similar to that of the SOZ/sodalite mixture to minimize, or even prevent, cracking during cool-down, 5) be free-flowing at the processing temperatures, 6) allow for packing of 40-45\% of theoretical density, 7) densify uniformly during heating, and 8) produce non-friable waste form surfaces.

During binder selection for the initial CWF work, several different glass binders were evaluated from Corning and Bayer [22], with compositions shown in Table 1. Bayer later became Pemco, and the P57 glass was selected and used until about 2005, when the company discontinued production. This was a commercial, off-the-shelf product that was never optimized but it worked well as a binder glass for the CWF process. Following P57, four new commercial glasses were evaluated that included Corning 7056, Schott 8250 K1, Schott 8250 Granular, and Johnson Matthey RD 808 [22]. A study was done to evaluate usage costs for these materials and, from this, it was apparent that the Corning 7056 glass (Table 1) was the most cost effective option and was selected as the recommended glass alternative to P57 [22]. In addition to these, other glasses have also been investigated for the CWF production including $\mathrm{Na}_{2} \mathrm{O}-\mathrm{B}_{2} \mathrm{O}_{3}$ $\mathrm{SiO}_{2}[11,14], \mathrm{Na}_{2} \mathrm{O}-\mathrm{Al}_{2} \mathrm{O}_{3}-\mathrm{P}_{2} \mathrm{O}_{5}[11,24]$, and $\mathrm{TeO}_{2}-\mathrm{PbO}$ [11] formulations.

The point of focus during glass binder formulation was a targeted $\sim 20$ mass $\% \mathrm{Na}_{2} \mathrm{O}$ that would provide extra Na for sodalite formation. The starting point for the current work was the NBS-1 glass (see Table 1) developed for immobilizing halide-rich Rocky Flats ash particles [25]. The NBS-1 glass made a good waste form and was demonstrated at near-full-scale $(19 \times 21.6-\mathrm{cm}$ canister $)[26]$. Each component in this glass was added for a specific reason. The 5 mass $\% \mathrm{Al}_{2} \mathrm{O}_{3}$ was added because, up to $\sim 5$ mass $\%$, 
$\mathrm{Al}_{2} \mathrm{O}_{3}$ is known to increase chemical durability in silicate glasses as it reduces non-bridging oxygens (NBO) strengthening the glass network [27-29]. The 5 mass $\%$ of $\mathrm{ZrO}_{2}$ was added to give this high silica formulation a sharper viscosity as a function of temperature $[\eta(T)]$ (i.e., make it a shorter glass [30]), as well as increase the chemical durability [31], a property effect that is most beneficial at low $\mathrm{ZrO}_{2}$ concentrations where Zr tightly bonds to 4 NBOs and 2 bridging oxygens [29]. The remaining components of $\mathrm{B}_{2} \mathrm{O}_{3}, \mathrm{Li}_{2} \mathrm{O}$, and $\mathrm{Na}_{2} \mathrm{O}$ were added to each glass in order to maintain the desired $\eta(T)$, transition temperature $\left(T_{\mathrm{g}}\right), \mathrm{CTE}$, and chemical durability using predictive glass-property models [32, 33].

The five additional binder glasses formulated for the current work include NBS-2, NBS-3, NBS4, NBS-5, and NBS-6. In all of these glasses, the target $\mathrm{Na}_{2} \mathrm{O}$ content was 20.17 mass $\%$. This value is the combination of the originally targeted 20 mass $\%$ plus the $\mathrm{Na}_{2} \mathrm{O}$ contribution from the $\mathrm{Na}_{2} \mathrm{SO}_{4}$ fining agent [34], remaining following decomposition during the melting process to achieve a bubble-free glass (described in more detail in section 4.1). The NBS-2 glass is based off NBS-1 but with higher $\mathrm{Na}_{2} \mathrm{O}$ and no $\mathrm{Li}_{2} \mathrm{O}$. An equimolar exchange of $\mathrm{Li}_{2} \mathrm{O}$ for $\mathrm{Na}_{2} \mathrm{O}$ meant 24.1 mass $\% \mathrm{Na}_{2} \mathrm{O}$, which seemed too high as a starting point considering that higher alkali leads to reduced chemical durability. Instead, an equimass exchange was chosen, i.e., $\sim 20 \% \mathrm{Na}_{2} \mathrm{O}$. For this glass, $\sim 5$ mass $\%$ of $\mathrm{ZrO}_{2}$ was added to increase the chemical durability and shorten the $\eta(T)$.

For the NBS-3 glass, the $\mathrm{Al}_{2} \mathrm{O}_{3}$ was increased to $\sim 9$ mass $\%, \mathrm{~B}_{2} \mathrm{O}_{3}$ was decreased to 9 mass $\%$, and the mass ratios of Si:B and Si:Al were the same as those used for L4-99, a glass that showed a minimum release for Si during the MCC-1 chemical durability test in a previous study by Kim et al. [35] at a fixed $\mathrm{Al}_{2} \mathrm{O}_{3}$-content of 9 mass $\%$. To this glass, $\sim 3$ mass $\%$ of $\mathrm{ZrO}_{2}$ was added to increase durability and shorten the $\eta(T)$.

For NBS-4, some thought was given towards the CTE of chlorosodalite, which changes with composition $\left(\sim 5-20 \times 10^{-6} \mathrm{~K}^{-1}\right)$ [36]. According to the nuclear waste glass composition variation study (CVS) [33], the CTE of high-SiO 2 glasses was increased by adding alkali or alkaline earth oxides, and/or by decreasing $\mathrm{Al}_{2} \mathrm{O}_{3}, \mathrm{ZrO}_{2}$, and $\mathrm{SiO}_{2}$ (B had a mixed effect). Since the alkali loading was already high, an alkaline earth oxide was added in the form of $\mathrm{CaO}$. This was chosen because it has less of a negative 
durability impact compared to $\mathrm{MgO}[37,38]$. The value chosen was 4 mass $\% \mathrm{CaO}$ because that has been shown to be near-ideal for $\mathrm{Ca}, \mathrm{Si}$, and $\mathrm{Na}$ in a previous study [35] where the chemical durabilities of similar glass compositions were evaluated. The composition chosen for NBS-4 was similar to L6-549 from a previous study [39], which had good response during the product consistency test [40] and moderate durability per the single-pass flow-through test [41], both of which are used to evaluate chemical durability [28]. Then, $\sim 2$ mass $\% \mathrm{ZrO}_{2}$ was added in place of $\sim 2$ mass $\% \mathrm{SiO}_{2}$ to help increase the chemical durability and shorten the $\eta(T)$.

For the NBS-5 glass, a different approach was taken. Here, starting from NBS-3, the $\mathrm{B}_{2} \mathrm{O}_{3}$ was increased to $\sim 16.5$ mass $\%$ and $\mathrm{SiO}_{2}$ was decreased while keeping $\mathrm{Al}_{2} \mathrm{O}_{3}$ fixed at $\sim 9$ mass $\%$. The $\mathrm{P} 57$ glass performs well as a glass binder for the CWF process and it has high $\mathrm{B}_{2} \mathrm{O}_{3}$, so this was one of the reasons for increasing the $\mathrm{B}_{2} \mathrm{O}_{3}$ content; the other was that it would help reduce the $\eta(T)$. Also, some extra $\mathrm{ZrO}_{2}$ was added ( $\sim 3.5$ mass $\%)$ in response to lowering the $\mathrm{SiO}_{2}$ to help increase the durability and shorten the $\eta(T)$

For NBS-6, a similar approach was taken to the NBS-5 glass by using the same $\mathrm{Si}: \mathrm{Al}$ and $\mathrm{Si}: \mathrm{Zr}$ mass ratios, but with a higher $\mathrm{B}_{2} \mathrm{O}_{3}$ loading. The $\mathrm{B}_{2} \mathrm{O}_{3}$ content used for NBS- 6 was the same as that for the P57 glass. The $\mathrm{Na}_{2} \mathrm{O}$ content was the same as the other NBS-\# glasses (20.17 mass\%). The goal of adding $\mathrm{B}_{2} \mathrm{O}_{3}$ here was to lower the $T_{\mathrm{e}}$ and $T_{\mathrm{s}}$ closer to that of the P57 glass, to help facilitate consolidation and the collapse of open porosity during the heat-treatment process.

\section{Methods}

\subsection{Glass fabrication and characterization}

\subsubsection{Glass batching and melting}

Glasses were fabricated in 200-g batches from stoichiometric amounts of oxides $\left(\mathrm{SiO}_{2}, \mathrm{ZrO}_{2}\right)$, $\mathrm{Al}(\mathrm{OH})_{3}, \mathrm{H}_{3} \mathrm{BO}_{3}$, and carbonates $\left(\mathrm{Na}_{2} \mathrm{CO}_{3}, \mathrm{CaCO}_{3}\right)$ using $99+\%$ pure chemicals and a PM4600 balance (Mettler Toledo, Columbus, $\mathrm{OH}$ ) with compositions shown in Table 1. Once batched, the powders were 
mixed in an agate mill within an Angstrom ${ }^{\circledR}$ milling machine. Mixtures were melted at the temperatures shown in Table 1 for 30 min within a Pt/10\%Rh crucible with a Pt/10\%Rh lid and quenched onto an Inconel pour plate. The glass was ground in a tungsten carbide mill within a vibratory fixture. Then, 0.5 mass $\%$ of $\mathrm{Na}_{2} \mathrm{SO}_{4}$ was added as a fining agent, and the mixture was melted at the same temperature as before for 30 min. Following the 30-min soak, some of the melt was poured into a steel mold, annealed at $600{ }^{\circ} \mathrm{C}$ for $4 \mathrm{hrs}$, and slow-cooled to room temperature at $1{ }^{\circ} \mathrm{C} \min ^{-1}$; the rest of the melt was quenched on the Inconel pour plate.

\subsubsection{Dilatometry}

For dilatometry, several $4 \times 4 \times 25-\mathrm{mm}$ bars with parallel faces were cut from the annealed glass bars using a CT400 diamond wire saw (Diamond Wire Technology, LLC, Colorado Springs, CO). The initial length of each bar was measured with a set of calipers to the nearest $0.01 \mathrm{~mm}$ and it was loaded into a quartz holder in a dilatometer (Dilatronic, Theta Industries, Inc., Port Washington, NY). Each specimen was heated from room temperature to a maximum temperature between 600 and $650{ }^{\circ} \mathrm{C}$ at $1{ }^{\circ} \mathrm{C}$ $\min ^{-1}$ where the furnace was then turned off to cool to room temperature. Trendlines were fit to the continuous-slope regions so the $T_{\mathrm{g}}$ and $T_{\mathrm{s}}$ (also called the dilatometric softening temperature or $T_{\mathrm{d}}$ ) temperatures could be determined by the intersection of these trendlines (see Figure 2). The slopes of the trendlines fitted to these continuous-slope regions, namely CTE region 1 or $T<T_{\mathrm{g}}$ and CTE region 2 or $T_{\mathrm{g}}$ $<T<T_{\mathrm{s}}$ (see Figure 2) were the derived CTE values. These continuous-slope temperature ranges were determined separately and manually for each run with a target correlation coefficient $\left(R^{2}\right)$ of 0.999 , which was not attainable in some cases. Each glass was run in duplicate except P57, which was only run once to verify that the results were close to the values reported by O'Holleran [42]. Prior to measurements, the instrument was calibrated with a SRM-732 single-crystal sapphire thermal expansion standard [43].

\subsubsection{Helium pycnometry}

The bulk density of each binder glass was measured using the bubble-free glass chunks remaining after the dilatometry bars were cut from the annealed blocks. The volume of each glass was measured 
using a He pycnometer (Micromeritics AccuPyc II 1340, Norcross, GA) through a series of 5 purges and 10 measurements that were averaged. Mass values were measured with an XPE205 analytical balance (Mettler Toledo) and then the pycnometer calculated the average bulk pycnometric density, $\rho_{\mathrm{b}, \mathrm{p}}$.

\subsection{Ceramic waste form fabrication and characterization}

\subsubsection{Salt simulant preparation}

The salt simulant was made starting with high ( $\geq 99.99 \%)$ purity, anhydrous salts from either Sigma Aldrich (St. Louis, MO) or Alfa Aesar (Haverhill, MA) and all work was done in an Ar glovebox. All salt components were mechanically mixed in a large polyethylene container and then poured into one of two alumina crucibles $(4.6 \times 15.2 \mathrm{~cm})$. The crucibles were placed into a furnace (Applied Test Systems, Butler, PA) and heated to $550{ }^{\circ} \mathrm{C}$ for $\sim 1 \mathrm{hr}$. The molten salt was then poured from the crucible into a stainless steel tray and cooled. After the first melt, the salt was collected and ground to a powder using a grinder (Mazzer, Venezia, Italy) and remixed. A second melt of the salt was performed similarly to the first melt, collected, ground to a powder, and mechanically mixed. The analyzed composition of the asmade salt using inductively-coupled plasma mass spectrometry is provided in Table 2.

\subsubsection{CWF and ACWF fabrication}

Zeolite 4A in $0.5 \mathrm{~mm}$ spherical form with $\sim 4$ mass\% clay binder (UOP, Des Plaines, IL) was ground to powder using a roller mill. A 45-250- $\mu \mathrm{m}$ sized fraction of ground zeolite was collected with sieves (Gilson Company, Lewis Center, $\mathrm{OH}$ ). The sized zeolite powder was then dried by placing it into a $\sim 2 \mathrm{~L}$ vacuum-tight steel vessel with an inlet and outlet. Once the drying vessel was loaded and sealed, it was placed into a large, vertically-oriented, cylindrical furnace and heated to $500{ }^{\circ} \mathrm{C}$ under a continuous Ar-gas flow through the vessel while at temperature. The vessel was heated at a ramp rate of $\sim 10{ }^{\circ} \mathrm{C} \min ^{-1}$ to $\sim 150{ }^{\circ} \mathrm{C}$ with a hold point of several hours so that the large amount ( 22 mass $\left.\%\right)$ of water vapor could be released from the zeolite. After this soak, the temperature was increased to $500{ }^{\circ} \mathrm{C}$ and held for $28 \mathrm{hrs}$ under a continuous Ar flow of approximately $0.2 \mathrm{~L} \mathrm{~min}^{-1}$. After the vessel had cooled to room 
temperature, the inlet and outlet valves were closed and the vessel was transferred to an Ar glovebox where the powder was remove from the vessel. All subsequent zeolite powder handling was performed under an inert atmosphere to prevent rehydration of the zeolite.

The moisture content of the zeolite after drying was determined by Karl Fischer titration (Mitsubishi CA-200, Chesapeake, VA, USA). The titrator was connected to a high temperature furnace where the powdered sample was introduced. As moisture evolved from the sample, it was swept into a flowing inert gas and to the reaction/titration vessel where moisture was quantitatively determined. The average moisture content of the dried zeolite was determined to be $0.24 \pm 0.06$ mass $\%$.

Salt occlusion into the zeolite was performed by hand-mixing the targeted amount (Table 3) of powdered salt (Table 2) and the dried zeolite powder in a sapphire mortar and pestle within the Ar glovebox. Then, this mixture was placed into a $200 \mathrm{~mL}$ glassy carbon crucible, and into a furnace at $500{ }^{\circ} \mathrm{C}$ for $2 \mathrm{hr}$. The mixture was removed from the furnace, remixed for several minutes, and placed back into the furnace for another 2 hrs. This process was repeated three additional times. After the final mixing, the mixture was left in the furnace for $12 \mathrm{hrs}$ and mixed one last time before cooling to ambient temperature.

To measure the degree of salt occlusion into the zeolite structure, a free $\mathrm{Cl}^{-}$analysis was performed. This method involved taking a number of $0.5 \mathrm{~g}$ samples from each mixture batch and adding each sample to $30 \mathrm{~mL}$ of demineralized water and shaking vigorously for $1 \mathrm{~min}$. The solution was then immediately filtered through a $0.45-\mu \mathrm{m}$ filter. The concentration of $\mathrm{Cl}^{-}$was analyzed in the collected water fraction with an ion-selective electrode (Orion 290A meter, Thermo Scientific, Waltham, MA, USA). The average free $\mathrm{Cl}^{-}$concentration was $0.151 \pm 0.012 \mathrm{Cl}^{-}$mass $\%$, well below the 0.5 mass $\%$ threshold as described in the CWF process description [22].

To fabricate a majority of the CWF and ACWF samples, a 50 g mixture of SOZ and the appropriate glass component (74-250 $\mu \mathrm{m}$ or $-60 /+200$ mesh) was mixed in a mortar and pestle then poured into a 200-mL glassy carbon or alumina crucible (see Table 3). The crucibles were then heated to $925^{\circ} \mathrm{C}$ for the times specified in Table 3 within an Ar glovebox. The sample naming convention for CWF 
and ACWF samples was CWF-XP-Y and ACWF-XN\#-Y for P57 and NBS-\# (abbreviated N\#) samples, respectively, where $\mathrm{X}$ and $\mathrm{Y}$ denote the mass\% of glass binder and salt, respectively, in the final waste form. In general, the glass component in the final pucks was 26 mass $\%$, except for CWF-52P-8 (52\% P57 glass), CWF-25P-8 (25\% P57), and ACWF-40N4G-10 (40\% NBS-4). An exception from the normal for ACWF-26N4f-11 was that a finer starting material was used for all of the reactants - for the zeolite 4A and glass binder, $<74-\mu \mathrm{m}(<200 \mathrm{mesh})$ powders were used, and for the salt, a finer-ground material (size was not determined) was used (see Table 3).

\subsubsection{Scanning electron microscopy and energy dispersive spectroscopy}

One of the sections of each CWF and ACWF was vacuum-impregnated with resin and polished in glycol-based diamond suspensions to a 250-nm finish. The SEM analysis was performed on the polished cross-sections with a JSM-7001F field-emission gun microscope (JEOL USA, Inc. Peabody, MA) using a backscattered electron (BSE) detector for atomic number contrast. All samples were first sputter-coated with Pt (Polaron Range SC7640, Quorum Technologies Ltd., East Sussex, England). The EDS analysis was performed with a Bruker xFlash ${ }^{\circledR} 6 \mid 60$ (Bruker AXS Inc., Madison, WI). The EDS dot mapping was performed at 110-130 $\mathrm{k} \mathrm{counts} \mathrm{s}^{-1}$ with a $\sim 51-$ min collection time over $1024 \times 768$ pixels at a $16-\mu$ s dwell time per pixel. Linescans were performed on the collected maps using 512 vertical data points that were averaged along the horizontal data collection line.

\subsubsection{Powder X-ray diffraction}

The P-XRD was used to analyze a section from each CWF and ACWF with a Bruker D8 Advance diffractometer $\left(\mathrm{Cu} \mathrm{K} \mathrm{K}_{\alpha}\right.$ line). The XRD had a LynxEye ${ }^{\mathrm{TM}}$ position-sensitive detector with a collection window of $3^{\circ} 2 \theta$. Scan parameters were $5-75^{\circ} 2 \theta$ with a step of $0.015^{\circ} 2 \theta$ and a 0.6 -s dwell at each step. For quantification, NIST SRM-674b $\left(\mathrm{TiO}_{2}\right)$ [44] was added at $\sim 5$ mass $\%$ so that the amorphous fraction could be determined. Bruker $\mathrm{AXS}^{\odot}$ EVA (v14) and Topas (v4.2) software were used to identify and quantify phase assemblages. Rietveld refinements were performed using whole-pattern fitting according to the fundamental parameters approach [45]. 


\subsubsection{Hot-stage X-ray diffraction}

The HS-XRD was run on a powdered sample of ACWF-26N4-11. A small amount of powdered sample was mixed with ethanol and pipetted onto a platinum heater strip (sample holder) and was left to dry. The system was set to collect spectra at $30{ }^{\circ} \mathrm{C}, 100{ }^{\circ} \mathrm{C}$, every $50{ }^{\circ} \mathrm{C}$ from $100{ }^{\circ} \mathrm{C}$ to $1050{ }^{\circ} \mathrm{C}$, and then at $30{ }^{\circ} \mathrm{C}$ once it was cooled back down to room temperature, with a 15 -min delay at each temperature prior to scanning to account for any thermal lag in the system between the set point and actual temperatures. The scanning parameters were $10-70^{\circ} 2 \theta$ with a step of $0.015^{\circ} 2 \theta$ and a 0.7 -s dwell at each step using $0.6^{\circ}$ soller slits using the LynxEye ${ }^{\mathrm{TM}}$ position-sensitive detector. The data was analyzed using EVA and Topas software. The CTE for sodalite and Pt were calculated using Equation (2) where $a_{T}$ is the

unit cell parameter (in $\AA$ ) at the instantaneous temperature $(T)$ and $a_{T_{0}}$ is the unit cell parameter (in $\AA$ ) at the initial temperature $\left(T_{0} ; 30{ }^{\circ} \mathrm{C}\right)$; these values were then compared to literature values $[36,46]$.

$$
\operatorname{CTE}\left(\mathrm{K}^{-1}\right)=\left(\frac{1}{a_{T_{0}}}\right)\left(\frac{a_{T}-a_{T_{0}}}{T-T_{0}}\right)
$$

\subsubsection{Time-of-flight secondary ion mass spectrometry}

The ToF-SIMS (TOF.SIMS5, IONTOF GmbH, Münster, Germany) was used to perform elemental mapping on select specimens with a lateral resolution of $\sim 200 \mathrm{~nm}$. A $\sim 10 \mathrm{~nm}$ layer of Au was deposited on the specimen surface to reduce the charging effects. To remove the Au layer for analysis and remove possible surface contamination, a $1.0 \mathrm{keV} \mathrm{O}_{2}{ }^{+}$beam was used as a sputter beam, which was scanned on a $200 \times 200-\mu \mathrm{m}^{2}$ area until a stable signal was obtained. Analysis was performed by scanning a $25.0 \mathrm{keV} \mathrm{Bi}{ }^{+}$beam at a current of $0.27 \mathrm{nA}$ on a $20 \times 20-\mu \mathrm{m}^{2}$ area around the center of the $\mathrm{O}_{2}{ }^{+}$crater. More experimental details are available in a separate paper on this technique [47]. The relatively high $\mathrm{Na}^{+}$ signal noise is due to a Poisson correction needed as a result of the dead time during signal counting. The secondary ion images were taken after the $\mathrm{O}_{2}{ }^{+}$beam cleaning, with $256 \times 256$ pixels per image for all measurements. 


\subsubsection{Atom probe tomography}

Specimens for APT were extracted from a polished cross-section onto a Si micropost array using standard focused ion beam (FIB) lift-out procedures with a dual-beam SEM/FIB (FEI Quanta and FEI Helios Nanolab 600, Hillsboro, OR) [48]. Samples were then sharpened into the necessary conical specimen geometry using annular mill patterns with $30 \mathrm{kV} \mathrm{Ga}^{+}$ions, while final specimen cleanup to minimize ion-beam damage was performed with $2 \mathrm{kV} \mathrm{Ga}^{+}$ions. The APT analysis was carried out using a LEAP 4000X HR equipped with a 355 nm UV laser (CAMECA, Société par Actions Simplifiée, France). The pulse energy was chosen to be $120 \mathrm{pJ}$ and the pulse frequency was increased from 125 to $250 \mathrm{kHz}$ during the experiment. Low frequencies were chosen to include ions with a higher mass-charge-state ratio at the low voltages in the beginning of the experiment. The specimen base temperature was $40 \mathrm{~K}$. Atom probe data reconstruction and analysis was performed using the CAMECA IVAS ${ }^{\circledR}$ software.

\subsubsection{Porosity and density measurements}

\subsubsection{Archimedes porosity and density}

Archimedes' approach was used to assess the porosity and density of the CWF and ACWF specimens. Here, the specimen masses were measured dry $\left(m_{\mathrm{dry}}\right)$ on either a ME204E (Mettler Toledo) or AP310 (Ohaus Corporation, Parsippany, NJ) analytical balance and then submerged in absolute EtOH within a vacuum desiccator where the air was removed from the open porosity and these voids were backfilled with absolute EtOH. After at least 20 min of sitting in the ethanol under vacuum (1.3-6.7 Pa), the submerged mass $\left(m_{\text {sub }}\right)$ was measured using an Archimedes density kit (ME-DNY-4) from Mettler Toledo. Then, the pellet was removed from the EtOH and the excess EtOH on the surface of the pellet was removed by blotting it on an EtOH-soaked cloth, and the pellet saturated with EtOH was weighed $\left(m_{\text {sat }}\right)$. The temperature of the EtOH was monitored and used to calculate the bulk Archimedes density $\left(\rho_{\mathrm{a}}\right)$ of the pellet according to Equation (3) where the $\rho_{\text {EtOH }}$ was the density of ethanol $\left(\rho_{\text {EtOH }}=-8.54 \times 10^{-4} * T+\right.$ $0.806 ; T=15-25^{\circ} \mathrm{C}$ [49]). From these data, the open porosity $\left(\phi_{\mathrm{a}}\right)$ of the specimens was measured based on mass differences as seen in Equation (4) [50]. 


$$
\begin{gathered}
\rho_{\mathrm{a}}=\left(m_{\mathrm{dry}} * \rho_{\mathrm{EtOH}}\right) /\left(m_{\mathrm{sat}}-m_{\mathrm{sub}}\right) \\
\phi_{\mathrm{a}}=\left(m_{\mathrm{sat}}-m_{\mathrm{dry}}\right) /\left(m_{\mathrm{sat}}-m_{\mathrm{sub}}\right)
\end{gathered}
$$

\subsubsection{Bulk geometric density}

Bulk geometric densities, $\rho_{\mathrm{b}, \mathrm{g}}$, were measured for each specimen. Here, a rectangular prism (mostly cubic) of each specimen was cut using an IsoMet ${ }^{\circledR}$ diamond saw (Buehler, Lake Bluff, IL) and polished with 400-grit sandpaper so that opposite faces were as parallel as possible. Absolute ethanol was used as the fluid during cutting and polishing to minimize dissolution of unincorporated salts. Then, the geometric dimensions were measured using a set of digital calipers $( \pm 0.01 \mathrm{~mm}, \mathrm{CD}-6 ”$ ASX, Mitutoyo, Kanagawa, Japan) where each set of three parallel faces were measured 6 times (each edge and then both diagonals) and then averaged. The volume was calculated from the average distances between each pair of parallel faces. The masses were then measured using the ME204E analytical balance and the density was calculated, i.e., $\rho_{\mathrm{b}, \mathrm{g}}=m V^{-1}\left(\mathrm{~kg} \mathrm{~m}^{-3}\right)$.

\subsubsection{Bulk pycnometric density}

The bulk pycnometric densities, $\rho_{\mathrm{b}, \mathrm{p}}$. for each specimen were measured using the same cubes as those used for measuring $\rho_{\mathrm{b}, \mathrm{g}}$. The volume of each glass was measured using a He pycnometer (Micromeritics AccuPyc II 1340, Norcross, GA) through a series of 5 purges and 10 measurements that were averaged. Mass values were measured with an XPE205 analytical balance (Mettler Toledo) and then the pycnometer calculated the average bulk pycnometric density, i.e., $\rho_{\mathrm{b}, \mathrm{p}}=m V^{-1}\left(\mathrm{~kg} \mathrm{~m}^{-3}\right)$.

\subsubsection{Porosity using SEM micrographs}

Finally, the porosity was measured using image analysis of backscattered electron SEM micrographs taken at $85 \times$ using Adobe Photoshop Extended Edition (v3.0). The porosity was measured by selecting the shadowed color range and using the measurement tool to determine the area. When this area was compared to the full area of the micrograph, this gave the area\% of porosity in the specimen 
$\left(\phi_{\text {SEM }}\right)$. Each value presented is the area fraction averaged from 6 micrographs taken from different regions of the specimen.

\subsubsection{Density ratios based on theoretical density}

In order to assess the density in the CWF and ACWF materials, $\rho_{\mathrm{b}, \mathrm{g}}$ was compared with the theoretical density, $\rho_{\mathrm{t}}$. To calculate $\rho_{\mathrm{t}}$ values, Equation (5) was used

$$
\rho_{\mathrm{t}}=\sum_{i=1}^{N} m_{\mathrm{i}} \rho_{\mathrm{i}}
$$

where $m_{\mathrm{i}}$ and $\rho_{\mathrm{i}}$ are the mass fraction and densities of $i$-th phase in the final waste form, respectively. The value used for $\mathrm{NaCl}$ was $2.162 \times 10^{3} \mathrm{~kg} \mathrm{~m}^{-3}$ [51]; the value for chlorosodalite was $2.285 \times 10^{3} \mathrm{~kg} \mathrm{~m}^{-3}$, the average of $2.27 \times 10^{3} \mathrm{~kg} \mathrm{~m}^{-3}$ [52] (ICSD\#98812) to $2.30 \times 10^{3} \mathrm{~kg} \mathrm{~m}^{-3}$ [53] (ICSD\#166827); and the values used for the amorphous phase were the $\rho_{\mathrm{b}, \mathrm{p}}$ values measured for the glass binders used in each experiment. These $\rho_{\mathrm{t}}$ values have caveats and are considered estimations. First, the density of the sodalite in the samples might be slightly different from that of pure chlorosodalite considering the mixture of alkali present in sodalite here, i.e., Li, Na, K (and maybe Cs). Second, the residual glass composition present after the heat-treatment of SOZ and starting glass binder is different in than the starting glass, and thus, would have a different density; however, this was the best-case estimate that could be provided for final glass density without too much effort. Then, the density ratio (DR) was calculated for the final waste forms as the $\%$ of $\rho_{\mathrm{t}}$, shown in Equation (6).

$$
\mathrm{DR}=\rho_{\mathrm{b}, \mathrm{g}} / \rho_{\mathrm{t}} \cdot 100
$$

\subsubsection{Specific surface area}

Surface areas of CWFs and ACWFs were determined using a Micrometrics Surface Area Analyzer (Model 2020 Micrometrics Instrument Corporation; Norcross, Ga). Air-dried samples were placed in a glass flask and out-gassed for a minimum of $3 \mathrm{hrs}$ at $150{ }^{\circ} \mathrm{C}$ under vacuum $(0.4 \mathrm{~Pa})$ where physisorbed water and any volatile organics were removed. To determine dryness, the vacuum pumps were isolated and if a vacuum change of $<0.27 \mathrm{~Pa}$ in 5 min occurred, the sample was considered clean 
and dry. After degassing, each sample was immediately analyzed. The approach used to make the measurements is based on the multipoint adsorption equation using $\operatorname{Kr}(99.99 \%)$, and specific surface areas (SSA) were determined from the isotherm with the Brunauer-Emmett-Teller (BET) method [54].

\subsection{Residual glass determination for ACWF-26N4-11 (26N4-11-RG)}

\subsubsection{Formulating 26N4-11-RG}

When the glass binder is heated in contact with the SOZ, components from the glass and SOZ phases exchange. Following this exchange, a residual glass is created that is similar to the starting glass but with several added components that do not incorporate into either the halite or sodalite phases. In order to compare the CTE properties of the sodalite in ACWF-26N4-11 (determined with HS-XRD) with that of the glass present while the waste form was cooling, the residual glass present in ACWF-26N4-11 was calculated using the approach described below.

In order to determine the residual glass composition, a phase (sodalite, halite, glass) componentdistribution-optimization routine was performed using the Evolutionary solving method for the Solver function in Microsoft Excel while minimizing the sum of squares with a $1 \times 10^{-9}$ convergence and a 0.5 mutation rate. Since the full composition of the sample was known, the starting elemental distribution (on a molar basis) was fixed. Several constraints were introduced into the calculation including (in order of weighted importance): the phase distribution based on bulk quantitative P-XRD analysis, partitioning of specific components to the glass phase (i.e., minimizing halides in glass fraction), alkali ratios between the sodalite and glass phases (i.e., ToF-SIMS data), the molar stoichiometry of $\mathrm{Na}$ and $\mathrm{Cl}$ in halite (i.e., $\mathrm{Na}: \mathrm{Cl})$, and the target molar stoichiometry of sodalite based on $[\text { alkali }]_{8}\left(\mathrm{AlSiO}_{4}\right)_{6}[\text { halide }]_{2}$. Other values were available but not used including sodalite:glass ratios measured with EDS; these were excluded due to the interaction volume artifacts from EDS, and since oxygen was not included in the calculations, the values had more uncertainty than ToF-SIMS values. Some assumptions were made regarding the expected phase location of various components, i.e., B, Ca, Cs (mostly), La, Y, Sr, Nd, Ce, and Zr partition completely to glass and $\mathrm{Cl}$ and I partition completely to the sodalite and halite phases. 
All optimization parameters were adjusted using a weighting factor, $w_{\mathrm{f}}$, and the sum of squares (SOS), where the squares were the difference between the target (or measured, if available) value $\left(p_{\mathrm{t}}\right)$ and the calculated value $\left(p_{c}\right)$ for a given parameter as shown in Equation (7). The optimization was performed while requiring a complete mass balance in the calculated waste form (i.e., component mass fractions in the feed material were set to equal those in the final calculated waste form). The calculated glass composition, called 26N4-11-RG, following a few iterations with Solver, is shown in Table 4, and the final optimization parameters are shown in Table 5.

$$
\operatorname{SOS}=\sum_{i=1}^{n}\left(p_{t}-p_{c}\right)^{2} w_{f}
$$

\subsubsection{Making 26N4-11-RG}

Using the composition presented in Table 4, the 26N4-11-RG glass was batched using $\mathrm{Al}(\mathrm{OH})_{3}$, $\mathrm{H}_{3} \mathrm{BO}_{3}$, carbonates $\left(\mathrm{CaCO}_{3}, \mathrm{Cs}_{2} \mathrm{CO}_{3}, \mathrm{~K}_{2} \mathrm{CO}_{3}, \mathrm{Li}_{2} \mathrm{CO}_{3}, \mathrm{Na}_{2} \mathrm{CO}_{3}\right)$, and oxides $\left(\mathrm{La}_{2} \mathrm{O}_{3}, \mathrm{Nd}_{2} \mathrm{O}_{3}, \mathrm{SiO}_{2}, \mathrm{Y}_{2} \mathrm{O}_{3}\right.$, and $\left.\mathrm{ZrO}_{2}\right)$. The $\mathrm{CeO}_{2}$ was omitted from the glass because the mass was too small $(0.0004 \mathrm{~g})$ to weigh out with high precision and was only present in the original calculation because it was a measured impurity in the original salt, likely from one of the other rare earth additives. The glass was fabricated following the procedures described in section 3.1.1 and was prepared for dilatometry and characterized using the procedures described in section 3.1.2. This glass was batched with less than targeted $\mathrm{Na}_{2} \mathrm{O}$ so that the after the $\mathrm{Na}_{2} \mathrm{O}$ from the $\mathrm{Na}_{2} \mathrm{SO}_{4}$ was incorporated into the glass, the final $\mathrm{Na}_{2} \mathrm{O}$ concentration was the target concentration.

\section{Results and Discussion}

\subsection{Binder glass characterization}

When P57 frit was melted, cast, and annealed for making bars for dilatometry measurements, it was apparent that a fining agent would have to be added to the glass to remove bubbles and create a fully dense glass bar. Thus, 0.5 mass $\% \mathrm{Na}_{2} \mathrm{SO}_{4}$, a commonly used low-temperature fining agent [34], was 
added to the P57 frit so that a bubble-free bar could be cast and reduce artifacts in the data due to these voids. The chemical reaction that $\mathrm{Na}_{2} \mathrm{SO}_{4}$ undergoes in a silicate melt is shown in Equation (8) [34].

$$
\mathrm{Na}_{2} \mathrm{SO}_{4} \text { (melt) } \rightarrow \mathrm{Na}_{2} \mathrm{O} \text { (melt) }+\mathrm{SO}_{2(\mathrm{~g})}+1 / 2 \mathrm{O}_{2(\mathrm{~g})}
$$

A visual comparison between two pieces of P57, one with $\mathrm{Na}_{2} \mathrm{SO}_{4}$ and one without, is shown in Figure 3, where the glass without $\mathrm{Na}_{2} \mathrm{SO}_{4}$ contained a multitude of small bubbles and the glass with $\mathrm{Na}_{2} \mathrm{SO}_{4}$ was bubble-free. Each glass evaluated here poured at moderately high viscosities, even at the

high melting temperatures of $1350-1550{ }^{\circ} \mathrm{C}$ (Table 1 ). The different $\rho_{\mathrm{b}, \mathrm{p}}$ values for the glass binders are presented in Table 6 along with the $T_{\mathrm{g}}, T_{\mathrm{s}}$, and CTE values at various temperature ranges of continuous slope $\left(T<T_{\mathrm{g}}\right.$ and $T_{\mathrm{g}}<T<T_{\mathrm{s}}$ ). The $T_{\mathrm{g}}$ and $T_{\mathrm{s}}$ values measured for $\mathrm{P} 57$ with added $\mathrm{Na}_{2} \mathrm{SO}_{4}$ were very close (516 and $570{ }^{\circ} \mathrm{C}$, respectively) to those reported by O’Holleran [42] (507 and $567^{\circ} \mathrm{C}$, respectively). Even though all of the NBS-\# glasses met the criterion set forth by Bateman et al. [22] of making sure that the glass softening temperature was $<750{ }^{\circ} \mathrm{C}$, all of the NBS-\# glasses had notably higher $T_{\mathrm{g}}$ and $T_{\mathrm{s}}$ values than P57 at $\Delta T_{\mathrm{g}} \sim+36-54{ }^{\circ} \mathrm{C}$ and $\Delta T_{\mathrm{s}} \sim+15-38{ }^{\circ} \mathrm{C}$ where the closest glasses to P57 were NBS-4 $\left(\Delta T_{\mathrm{g}} \sim\right.$ $+27^{\circ} \mathrm{C}$ and $\left.\Delta T_{\mathrm{s}} \sim+12{ }^{\circ} \mathrm{C}\right)$ and NBS$-6\left(\Delta T_{\mathrm{g}} \sim+38^{\circ} \mathrm{C}\right.$ and $\left.\Delta T_{\mathrm{s}} \sim+15^{\circ} \mathrm{C}\right)$.

\subsection{CWF and ACWF characterization}

\subsubsection{Porosity, density, and specific surface area}

The $\rho_{\mathrm{b}, \mathrm{p}}, \rho_{\mathrm{b}, \mathrm{g}}, \rho_{\mathrm{a}}, \rho_{\mathrm{t}}, \phi_{a}, \phi_{\mathrm{SEM}}, \mathrm{DR}$, and SSA values for all CWF and ACWF samples are presented in Table 7. The as-made CWFs and ACWFs were $\sim 5-\mathrm{cm}$ in diameter and $\sim 2-\mathrm{cm}$ tall. The CWF-52P-8 sample was very dense, which was expected considering the high glass loading of 52 mass $\%$, and samples CWF-25P-8 and ACWF-40N4G-10 were also quite dense (see Table 7). The ACWFs with 11-14 mass\% salt (with NBS-\# glass binders) and CWF-26P-11 did not appear to fully densify during the heattreatment and all had a fairly similar appearance of moderate porosity; the $\rho_{\mathrm{b}, \mathrm{p}}, \rho_{\mathrm{b}, \mathrm{g}}, \rho_{\mathrm{a}}, \rho_{\mathrm{t}}, \phi_{a}, \phi_{\mathrm{SEM}}$, and DR values presented in Table 7 support these observations. The $\phi_{\mathrm{a}}$ value for CWF-52P-8 was measured at $0.74 \pm 0.48$ vol\%, CWF-26P-11 was $32.6 \pm 3.6 \%$ and the ACWFs (ACWF-26N\#-11) were all between $37-$ 
45 vol\% with ACWF-26N5-11 being the lowest. The $\phi_{\text {SEM }}$ values were comparable to the $\phi_{\mathrm{a}}$ values but different in some cases and generally had higher errors compared to the $\phi_{\mathrm{a}}$ values. These discrepancies are attributed to fact that only a small fraction of the specimen was analyzed during $\phi_{\mathrm{SEM}}$ measurements whereas the $\phi_{\mathrm{a}}$ values were taken as the averages of bulk measurements on much larger specimens. For the most part, the $\phi_{\mathrm{a}}$ and $\phi_{\mathrm{SEM}}$ values were in good agreement with one another.

The $\rho_{\mathrm{b}, \mathrm{p}}$ values for the NBS-4 series of samples made with different glass and salt loadings are presented in Figure 4. A steady decrease in $\rho_{\mathrm{b}, \mathrm{p}}$ values was observed in samples with increased salt loadings from $8 \rightarrow 11 \rightarrow 14$ mass\% in the series of samples made with 26 mass\% NBS-4 (ACWF-26N4$\# ; \#=8,11,14)$. This could be due to the lower density of the added salt compared to that of the glass and SOZ, to increased closed porosity, or both. The low $\rho_{\mathrm{b}, \mathrm{p}}$ value for ACWF-40N4G-10 is attributed to a higher degree of closed porosity due to the increased binder loading of 40 mass $\%$ compared to 26 mass $\%$, which was used for the other samples. The ACWF-26N4f-11 sample, which was made with finer-grained starting material than ACWF-26N4-11, showed lower porosity than ACWF-26N4-11 by $\sim 15 \%$ for $\phi_{\mathrm{a}}$ and $\sim 25 \%$ for $\phi_{\mathrm{SEM}}$ as well as higher $\rho_{\mathrm{b}, \mathrm{g}}(\sim 18 \%)$ and $\rho_{\mathrm{a}}(13 \%)$ values.

For CWF-52P-8, the $\rho_{\mathrm{b}, \mathrm{p}}\left(2.149 \times 10^{3} \mathrm{~kg} \mathrm{~m}^{-3}\right), \rho_{\mathrm{b}, \mathrm{g}}\left(2.113 \times 10^{3} \mathrm{~kg} \mathrm{~m}^{-3}\right)$, and $\rho_{\mathrm{a}}\left(2.127 \times 10^{3} \mathrm{~kg} \mathrm{~m}^{-3}\right)$ values revealed some closed porosity because all three values were lower than the density of the P57 glass at $2.2690 \times 10^{3} \mathrm{~kg} \mathrm{~m}^{-3}$ and the chlorosodalite phase, which literature shows ranges from $2.27 \times 10^{3} \mathrm{~kg} \mathrm{~m}^{-3}$ [52] (ICSD\#98812) to $2.30 \times 10^{3} \mathrm{~kg} \mathrm{~m}^{-3}$ [53] (ICSD\#166827). For the other samples, the $\rho_{\mathrm{b}, \mathrm{p}}$ values were close to expected values with slightly higher densities than sodalite due to the increased density of the added glass binders (Table 6).

One of the more interesting comparisons from Table 7 is the data for CWF-25P-8 and ACWF26N4-8 with similar glass loadings (25\% P57 and 26\% NBS-4, respectively) and identical salt loadings at 8\%. The CWF-25P-8 sample had much lower porosity ( $\phi_{a}=14.2$ vol\%) compared with ACWF-26N4-8 $\left(\phi_{a}=44.1 \mathrm{vol} \%\right)$. This shows that the P57 glass is more effective for lowering porosity at low salt loadings but the phase distributions were not ideal (this is discussed in section 4.2.3). 
Figure 5 shows some relationships between densities $\left(\rho_{\mathrm{a}}, \rho_{\mathrm{b}, \mathrm{g}}\right.$, and $\left.\rho_{\mathrm{b}, \mathrm{p}}\right)$ and porosities $\left(\phi_{\mathrm{a}}\right.$ and $\left.\phi_{\mathrm{SEM}}\right)$ for all CWFs and ACWFs. Figure 5a and Figure 5b show the relationships between $\rho_{\mathrm{b}, \mathrm{g}}$ and $\rho_{\mathrm{a}}$ as well as $\phi_{\mathrm{a}}$ and $\phi_{\mathrm{SEM}}$, respectively. When looking at Figure 5a, it is clear that $\rho_{\mathrm{a}}>\rho_{\mathrm{b}, \mathrm{g}}$ in all cases by a nearly constant amount demonstrating that the geometric and Archimedes' methods for determining density yield slightly different results. The trend in Figure 5 b shows a linear trend for both porosity measurement techniques but with some outliers on both sides of the line showing that these two techniques agree fairly well with one another with some exceptions. Figure $5 \mathrm{c}$ shows how values for $\rho_{\mathrm{a}}$ and $\rho_{\mathrm{b}, \mathrm{g}}$ decrease linearly with increased porosity $\left(\phi_{\mathrm{a}}\right)$, which was expected since neither take into account the skeletal density (excluding porosity) and as the $\phi_{\mathrm{a}}$ increased, the volume increased at a fixed mass. On the contrary, the values for $\rho_{\mathrm{b}, \mathrm{p}}$ consistently increased with increasing $\phi_{\mathrm{a}}$ and this was attributed to the higher degree of closed porosity observed during SEM analysis in the samples with lower $\phi_{\mathrm{a}}$ values, which was less of a factor when the open porosity allowed for more accessibility during the pycnometry measurements. All of these relationships were linear.

Figure 6 shows the densities (Figure $6 \mathrm{a} ; \rho_{\mathrm{a}}, \rho_{\mathrm{b}, \mathrm{g}}$, and $\rho_{\mathrm{b}, \mathrm{p}}$ ) and porosities (Figure $6 \mathrm{~b} ; \phi_{\mathrm{a}}$ and $\phi_{\mathrm{SEM}}$ ) as functions of SSA. It is expected that, as the porosity of the waste form increases, the SSA will also increase and this is seen as a general trend for both $\phi_{a}$ and $\phi_{\mathrm{SEM}}$. However, the porosity seemed to plateau as SSA increased across the dataset and this is attributed to smaller pores for the higher SSA samples. Regarding the densities, since neither $\rho_{\mathrm{a}}$ nor $\rho_{\mathrm{b}, \mathrm{g}}$ take skeletal density into account but rather the volumetric density, they followed a similar trend of decreasing with increased SSA while $\rho_{\mathrm{b}, \mathrm{p}}$ increased with increasing SSA because of lower closed porosities in samples with high SSA values.

All of the samples discussed here were made using a pressureless sintering procedure and the porosities in the fired products here higher than desired (Table 7). It is possible that this porosity could decrease with (1) larger sample volumes/masses due to more compressive force, (2) longer heat-treatment times due to increased flow of the binder glass, (3) a higher glass:SOZ ratio, (4) and/or hot pressing. In past studies for consolidating pure sodalite or glass-bonded sodalite, a range of processing conditions have been applied in addition to pressureless sintering [24] including cold-press-and-sinter [10, 11, 13, 
55], spark plasma sintering [55], and hot isostatic pressing [14, 56, 57]. It should be recognized that implementing a hot-pressing approach may complicate the process as the scale of the waste form increases. More work would be required to develop and optimize a process specific to these ACWFs.

\subsubsection{Microstructure and chemistry}

The SEM analyses of cross-sectioned samples are shown in Figure 7 and Figure 8, and a few obvious differences were observed between the samples. First, the sodalite domains were very apparent in all ACWFs by distinct contrast differences from the glassy phase, where the sodalite domains were darker. The glass phase was notably brighter achieved using the BSE detector. This contrast is very apparent in Figure 8 but can also be seen in Figure 7. For CWF-26P6-11 with the same SOZ:glass ratio as the ACWF-26N\#-11 samples, these distinct sodalite-glass boundaries were less noticeable and this is attributed to greater mixing between the SOZ and glass phases, evidenced by the higher amorphous fraction in the samples made with the P57 binder.

For CWF-52P-8, the sodalite-glass interface was even more difficult to locate based on contrast differences, but rather, was visible because of the void spaces within the sodalite domains, which can be seen in both Figure 7 and Figure 8, indicating closed porosity for the most part. The bulk EDS elemental analysis of select samples is shown in Figure 9 with EDS dot maps for CWF-52P-8, CWF-26P-11, and ACWF-26N5-11. As is seen in Figure 9, the concentration gradient trends were similar for all elements. The concentration of Si was higher in the glass phase than in the sodalite phase, the concentration of $\mathrm{Al}$ was higher in the sodalite phase than the glass phase, and the $\mathrm{Cl}$ was (nearly) fully concentrated in the sodalite phase. The $\mathrm{Sr}$ is shown as incorporating into the glass phase, which was expected based on the difficulty of incorporating alkaline earths into the sodalite structure [13].

A wide (vertically averaged) EDS linescan was collected on each sample similarly to that shown for CWF-52P-8, CWF-26P-11, and ACWF-26N2-11 in Figure 10. While only ACWF-26N2-11 is shown for the ACWF-N\#-11 set of samples, it is representative of what was observed for the others. Figure 10 reveals some finer detail with the compositional distribution between CWF-52P-8, CWF-26P-11, and 
ACWF-26N2-11 than can be captured by just comparing the EDS elemental dot maps. It should be noted that the sodalite-glass interface is not abrupt in the linescans. This is partly because of the data-point averaging used to collect the linescan data but also because the sodalite grains are distinct particles (not a solid phase) within a glassy matrix and the boundary is not exactly flat, i.e., the overlap in this boundary is denoted by dotted vertical lines in each SEM micrograph and corresponding linescan. Despite these caveats, the shapes of the linescans were quite different between the ACWF-26N\#-11 samples and the P57 samples (CWF-52P-8 and CWF-26P-11), and this was quite noticeable for $\mathrm{Si}, \mathrm{Al}, \mathrm{Na}, \mathrm{Sr}, \mathrm{K}$, and $\mathrm{Cl}$. For CWF-52P-8 and CWF-26P-11, on the right side of the sodalite-glass interface in Figure 10, the concentrations of $\mathrm{Na}, \mathrm{Si}$, and $\mathrm{Al}$ were still changing well into the glass phase. However, in ACWF-26N211 (as well as for all of the other ACWF-26N\#-11 samples), the composition of the glass phase was relatively constant past the sodalite-glass interface and into the glass. This data provides an example of a higher degree of interaction between the sodalite and glass phases in the samples made with the P57 glass binder.

\subsubsection{Phase distribution}

\subsubsection{P-XRD}

The phase distributions determined with P-XRD for the CWFs and ACWFs following heattreatment are presented in Table 7 and some of the P-XRD spectra are presented in Figure 11. The sodalite is believed to be almost entirely chlorosodalite $\left[\mathrm{Na}_{8}\left(\mathrm{AlSiO}_{4}\right)_{6} \mathrm{Cl}_{2}\right]$ as opposed to mixed hydroxychlorosodalite $\left[\mathrm{Na}_{8}\left(\mathrm{AlSiO}_{4}\right)_{6} \mathrm{Cl}_{(2-x)}(\mathrm{OH})_{x}\right]$ based on a variety of refinement iterations using combinations of these phases in the Topas software. If the hydroxysodalite is present, it is at concentrations $<2.5$ mass\%, although having it included in the refinement does not improve the fit (tracked as "Rwp"). These show that the sodalite yield for the ACWF-26N\#-11 samples were notably higher (57.4-69.0 mass\%) than CWF-52P-8 (8.5 mass\%) and CWF-26P-11 (38.9 mass\%). The fraction of unincorporated halite (NaCl) was 2.4-3.1 mass\% for the ACWF-26N\#-11 samples and was notably higher for CWF-P1-8 at 5.5 mass $\%$ and CWF-26P-11 at 4.2 mass\%. The amorphous phase fractions were higher than the added 
amount of glass binder by 6-119 relative\%. This means that, while the glass and SOZ phases interacted during the heat treatment, some of the zeolite phase dissolved in the glass phase rather than forming sodalite. This also suggests that the P57 glass was more reactive towards the zeolite phase than any of the NBS-\# glasses.

The phase distribution trends for the series of samples made with the NBS-4 glass binder are shown in Figure 12 with data from Table 7 . Here it can be seen that with increased salt loadings from $8 \rightarrow$ $11 \rightarrow 14$ mass $\%$ in the series of samples made with 26 mass\% NBS-4 (ACWF-26N4-\#; \#=8, 11, 14), the halite consistently increases while the amorphous fraction consistently decreases. The ACWF-26N4f-11 sample made with the same binder as ACWF-26N4-11 (NBS-4), but with smaller-grained starting materials, showed a $2.4 \%$ increase in sodalite yield over the ACWF-26N4-11 sample but with a slightly increased halite content of 3.6 mass $\%$ compared to 3.1 mass $\%$, respectively.

The ACWF-26N4-12 sample had a notably higher sodalite fraction of 68.8 mass $\%$ compared to the ACWF-26N4-11 sample at 63.1 mass\% but the halite fraction was slightly higher (3.6 mass\% versus 3.1 mass $\%$, respectively). It is difficult to know if this difference was influenced by the alumina crucible used in place of the glassy carbon crucible, because in the instance of ACWF-26N6-11-Al versus ACWF26N6-11 where the only difference was the crucible type, the values for phase distribution were similar (see Table 7). For ACWF-26N4-14, which had the highest salt loading of all the samples in the study at 14 mass $\%$, the halite content was the highest at 7.6 mass $\%$.

As discussed previously in section 4.2.1, the CWF-25P-8 sample had much lower porosity compared with ACWF-26N4-8, but the sodalite production was much lower at $42.3 \%$ versus $61.5 \%$, respectively, and the halite fraction was still at $1.9 \%$ versus $0.0 \%$, respectively. This shows that, while the porosity was lower when using the P57 glass at a comparable binder loading and identical salt loading to that of the NBS-4 binder, the phase distribution was superior for the NBS-4 binder over the P57 binder. 


\subsubsection{HS-XRD}

The HS-XRD experiment with ACWF-26N4-11 provided a method for looking at in-situ phase transitions at increasing temperatures without the artifacts produced by, instead, using pre-cooled samples separately heat-treated at the desired temperatures. However, it was difficult to control sample volatility during the HS-XRD experiment so this might have introduced some artifacts in the phase distributions if the volatility, due to sodalite decomposition, occurred incongruently for the various phases present. This sodalite decomposition comes in the form of salt volatilization according to the reaction shown in Equation (9). While this type of decomposition does not typically occur in larger sample volumes, it has been observed in several previous studies using small-scale samples such as in pellet studies $[11,58,59]$. Since the volume of sample used in the HS-XRD experiment was very small and spread thin on the Pt heater strip, this likely accelerated the sodalite decomposition process.

$$
\begin{aligned}
& \mathrm{Na}_{8}\left(\mathrm{AlSiO}_{4}\right)_{6} \mathrm{Cl}_{2} \stackrel{\Delta}{\rightarrow} 6 \mathrm{NaAlSiO}_{4}+2 \mathrm{NaCl} \\
& \text { (sodalite) (nepheline) (halite) }
\end{aligned}
$$

Figure 13 shows two waterfall plots obtained from the HS-XRD experiment on ACWF-26N4-11 in different angular scan ranges where the primary peak for sodalite is shown (Figure 13a, 24-25 $2 \theta$ ) and where peaks for sodalite and halite can be seen decreasing in intensity with temperature as nepheline peaks increase in intensity (Figure 13b, 26-36 $2 \theta$ ). These plots show the diffraction peaks shifting to lower $2 \theta$ angles with increasing temperature as the unit cell sizes increase due to thermal expansion. As the reaction progressed to higher temperatures, the mass fraction of halite decreased starting around 400$450{ }^{\circ} \mathrm{C}$ where the sodalite fraction increased (Figure 14). At a temperature of $\sim 700{ }^{\circ} \mathrm{C}$, the sodalite fraction began to decrease with increasing nepheline fraction.

\subsubsection{Thermal expansion}

The HS-XRD experiment with ACWF-26N4-11 provided some corroborating results to the aforementioned analyses. Most importantly, it provided a method for looking at the CTE of the sodalite in the CWF, which was a unique composition for the salts used here and different than those found in the 
literature [36]. As mentioned by Bateman et al. [22], thermal expansion is an important metric to consider when combining a glass binder with sodalite to prevent a CTE mismatch between the two bonded phases during the cool-down period, because a mismatch would likely result in cracking throughout the monolithic waste form. When forced (active) cooling was used during the large-scale CWF fabrication, the monolith was observed to crack using acoustical monitoring devices such as microphones [60], although these cracks were believed to be due to solidification stresses rather than thermal stresses. It remains uncertain whether these cracks compromise the integrity of the overall waste form.

The CTE values for the sodalite in ACWF-26N4-11 are presented in Figure 15a along with literature data [36] of chlorosodalite $\left(\sim 5-20 \times 10^{-6} \mathrm{~K}^{-1}\right)$ with different alkali distributions ( $\mathrm{Li}$, Na, and/or K) over the applicable temperature range. The literature data [36] seem representative for the general chemistry range that would be expected for the sodalite composition in ACWF-26N4-11 based on the range of the different alkali present in the sample before exchange (low $\mathrm{Na}$, high $\mathrm{K}$ plus Li) and after exchange (high $\mathrm{Na}$, low $\mathrm{K}$ and $\mathrm{Li}$ ) between the $\mathrm{SOZ}$ and glass phases. One caveat between the data presented by Henderson and Taylor [36] and that of the current study is that they did not include a composition with $\mathrm{Li}, \mathrm{Na}$, and $\mathrm{K}$ in a single sample, and the sodalite in the current study appears to have a mixture of all three, as discussed herein. Additionally, the data obtained for the platinum (from the heater strip) was corroborated with data from the literature [46] to assess validity of the experiment and this is shown in Figure 15b.

The CTE values for sodalite presented by Henderson and Taylor [36] were used in finding a glass with a comparable CTE value for the glass binders. As mentioned previously, glass has two different CTE values that can be calculated within two separate linear ranges of expansion with temperature, which are $T<T_{\mathrm{g}}(\mathrm{CTE}$ region 1$)$ and $T_{\mathrm{g}}<T<T_{\mathrm{s}}(\mathrm{CTE}$ region 2) (see Figure 2). The lower temperature range $(T<$ $T_{\mathrm{g}}$ ) encompasses the temperature region where the glass does not undergo flow and the upper temperature range $\left(T_{\mathrm{g}}<T<T_{\mathrm{s}}\right)$ is where the glass can still flow. The critical temperature region where cracking might occur most is near, but below, $T_{\mathrm{g}}$. 
Depending on the glass binder used, the CTE values in this critical temperature range varied and this was especially notable when comparing P57 with the NBS-\# glasses (Table 6 and Figure 16). The CTE values measured for P57 $\left(5.36 \times 10^{-6}\right.$ and $23.41 \times 10^{-6} \mathrm{~K}^{-1}$ for lower and higher regions, respectively) were significantly lower than all of those measured for the NBS-\# glasses (ranging $\sim 10.2-11.0 \times 10^{-6}$ and 72.4-98.0 $\times 10^{-6} \mathrm{~K}^{-1}$ for lower and higher regions, respectively). This shows that the pure NBS-\# glasses, or the glass before alkali exchange with the SOZ, have a closer CTE to that of sodalite than the P57 at the lower temperature range $\left(T<T_{\mathrm{g}}\right.$ ), which could help to reduce cracking in the final waste form during the cooling process due to thermal expansion mismatching. This difference could be the cause of the higher amount of voids present in the CWFs made with the P57 glass (CWF-P1-8 and CWF-P6-11) as opposed to the ACWF-N\#-11 samples made with the NBS-\# binders (see Figure 7, Figure 8, Figure 9, and Figure 10). The voids at the interfaces of the glass and sodalite for CWF-P1-8 and CWF-P6-11 may have been caused by a difference in thermal expansion between the two phases.

The CTE of the residual glass for ACWF-26N4-11, called 26N4-11-RG, is also presented in Figure 16 and the $T_{\mathrm{g}}$ and $T_{\mathrm{s}}$ values are shown in Table 6 . This CTE data is the most representative data that could be obtained for comparing the residual glass with that of the sodalite CTE for a given sample. As can be seen in Figure 16, the CTE data for sodalite (HS-XRD for ACWF-26N4-11) and the residual glass (26N4-11-RG) for the ACWF made with NBS-4 glass binder are very similar and this is further evidence of CTE-matching between the different phases present in this sample.

\subsubsection{Ion exchange}

Figure 9, Figure 10, Figure 17, Figure 18, and Table 8 all reveal evidence of alkali migration between the glass and SOZ phases during the heat-treatment using EDS, ToF-SIMS, and APT to track composition across the sodalite-glass interface in as-made CWF and ACWF materials. For all materials analyzed, $\mathrm{K}$ and $\mathrm{Li}$ were enriched in the glass phase and $\mathrm{Na}$ was enriched in the sodalite phase, despite the fact that none of the glass binders had any added K and the only glass with added Li was P57 with a very low $\mathrm{Li}_{2} \mathrm{O}$ content at 0.3 mass\% (Table 1). Evidence of this alkali exchange is shown for CWF-52P-8, 
ACWF-26N5-11, and CWF-26P-11 in Figure 9, for CWF-52P-8 and ACWF-26N2-11 in Figure 10, for ACWF-26N3-11 in Figure 17, and for ACWF-26N4-11 in Figure 18.

The summary of elemental comparisons between the glass and sodalite phases for a variety of samples using both EDS (averaged at\%, excluding oxygen) and ToF-SIMS (averaged counts) are presented in Table 8. The concentrations of Li were evaluated across the sodalite-glass interface for ACWF-26N3-11 (Figure 17) and ACWF-26N4-11 (not shown) with ToF-SIMS and were found to be $2.6 \times$ and $11.9 \times$ higher in the glass phases than the sodalite phases, respectively (Table 8 ). The ToF-SIMS results for ACWF-26N3-11 (Figure 17) and ACWF-26N4-11 with K showed 4.3× and 14.1× higher values in the glass than in the sodalite phase, respectively (Table 8). The EDS data was within the lower range of that for other samples evaluated at $2.6-12.5 \times$ higher concentrations in the glass compared to the sodalite phase, but may have been influenced by larger interaction zones encompassing more than one phase in each spot.

With the Li and $\mathrm{K}$ being depleted in the SOZ phase, Na was required to form sodalite [see Equation (1)] and this Na came from the glass. The distribution of Na originally in the glass phase was 20.2 mass $\% \mathrm{Na}_{2} \mathrm{O}$ or 15.0 mass $\% \mathrm{Na}$ and the amount of $\mathrm{Na}$ in a fully-exchanged $\mathrm{NaCl}$-sodalite, i.e., $\mathrm{Na}_{8}\left(\mathrm{AlSiO}_{4}\right)_{6} \mathrm{Cl}_{2}$, is $\sim 19$ mass $\%$. Thus, the mass of $\mathrm{Na}$ in the glass phase (mass $=m_{\mathrm{gl}}$ ) and the mass in the sodalite phase (mass $=m_{\text {sod }}$ ) are similar, which is where the Li and $\mathrm{K}$ contributions balance the reaction. The Na detected for ACWF-26N3-11 (Figure 17) and ACWF-26N4-11 using ToF-SIMS showed 1.88x and $2.04 \times$ higher values in the sodalite phase as compared to the glass phase, respectively, and this is corroborated by the range of values reported for EDS analysis at 1.30-2.23 $\times$ higher values for sodalite over glass shown in Table 8.

Using the data presented in Table 8 for the sodalite:glass ratio measured with EDS, the series of samples made using the NBS-4 glass binder are shown in Figure 19. In looking at the Na data, a steady increase occurred in the sodalite:glass ratio with a fixed binder loading (26 mass\%) and increased salt loadings from $8 \rightarrow 11 \rightarrow 14$ mass\% (ACWF-26N4-\#; \#=8, 11, 14). The sodalite:glass Na ratios for ACWF-26N4f-11 (2.00 \pm 0.28$)$ and ACWF-26N4-11 ( 2.04 \pm 0.18$)$ were almost identical, the value for 
ACWF-26N4-12 (made in the alumina crucible) showed the highest value in this dataset $(2.23 \pm 0.21)$, and

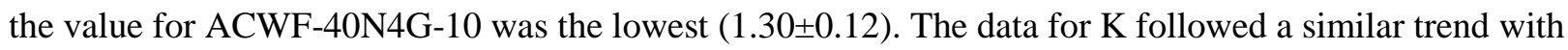
a fairly steady (slightly decreasing) ratio for sodalite:glass with increased salt loadings from $8 \rightarrow 11 \rightarrow 14$ mass\% in samples with 26 mass\% glass binder. The highest ratio, or the lowest gradient, was observed for ACWF-40N4G-10. These results show that as the salt content was increased, the compositional gradient in the alkali distribution also increased. When higher glass binder content was added in the case of ACWF-40N4G-10, this gradient was notably lowered.

These observations support the idea that, while alkali migration occurred between the SOZ and glass phases during the heat treatment, the $\mathrm{Na}$ was not fully concentrated into the sodalite phase and the $\mathrm{K} / \mathrm{Li}$ ions were not fully incorporated into the glass phase. However, it should be noted that the values obtained for all of these ions in the sodalite phase included an interdispersed glassy phase around the sodalite grains so analytical interaction volumes are a source of error in the measurements. The EDS analysis is not entirely a surface technique so some glass contribution is likely included in the values reported in Table 8, while ToF-SIMS is more of a surface technique so the values reported for sodalite should be more representative, without as much of a contribution from the residual glass.

However, despite these results, the measured counts for $\mathrm{Na}$ in the glass phase were not zero so the ion exchange likely did not go to completion. Interestingly, even though the $\mathrm{Na}_{2} \mathrm{O}$ content in the P57 glass (7.1 mass\%) was quite a bit lower than that of the NBS-\# glasses (20.2 mass\%), the alkali ratios for sodalite:glass (at\%) phases for samples made with these different glasses after firing were similar for $\mathrm{Na}$ at 2.0-2.13 (CWF-26P-11) and 1.30-2.23 (ACWF-26N\#-11; \# = 2, 3, 4, 5, 6), respectively, and for $\mathrm{K}$ at 0.09-0.38 (CWF-26P-11) and 0.08-0.28 (ACWF-26N\#-11; \# = 2, 3, 4, 5, 6), respectively. This suggests that the starting $\mathrm{Na}_{2} \mathrm{O}$ content in the glass binder did not significantly change the ratio of $\mathrm{Na}$ between the two phases, which was not expected. 


\section{Softening temperature model development}

In addition to the experimental work, a $T_{\mathrm{s}}$ model was generated to aid in predicting these values for new glasses. As a starting point for the models, SciGlass (v7.0, ITC, Inc., Newton, MA) was used to obtain data for glasses in the literature with $\geq 30$ mass $\% \mathrm{SiO}_{2}$ where $T_{\mathrm{s}}$ data were available [29, 61-137]. Additionally, $T_{\mathrm{s}}$ data obtained using dilatometry on glasses from the CVS study were also used, but this data was never published in the summary reports [33]. Including the 5 NBS-\# glasses from the current study, this compilation resulted in 585 individual glasses.

JMP® software (v10.0.2, SAS Institute Inc., Cary, NC) was used to evaluate various models to see how each component affected the $T_{\mathrm{s}}$ value. To start this process, models were generated using only $1^{\text {st }}$ order terms on a mass basis; the data was evaluated on a molar basis, but it did not seem to improve the fitting so mass values were used from that point forward. After several iterations, the final model had thirteen $1^{\text {st }}$ order terms that were found to be significant (i.e., $\mathrm{Al}_{2} \mathrm{O}_{3}, \mathrm{~B}_{2} \mathrm{O}_{3}, \mathrm{BaO}, \mathrm{CaO}, \mathrm{F}, \mathrm{K}_{2} \mathrm{O}, \mathrm{Li}_{2} \mathrm{O}$, $\mathrm{MgO}, \mathrm{Na}_{2} \mathrm{O}, \mathrm{SiO}_{2}, \mathrm{SrO}, \mathrm{ZnO}$, and $\mathrm{ZrO}_{2}$ ), a $1^{\text {st }}$ order term called the "Others" containing the sum of all of components found to not individually represented by a model term, and a single $2^{\text {nd }}$ order term of $\mathrm{Li}_{2} \mathrm{O} \times \mathrm{B}_{2} \mathrm{O}_{3}$; the final model coefficients, $s_{\mathrm{i}}$, can be found in Table 9 including the statistical values. The resulting model has the form shown in Equation (10),

$$
T_{\mathrm{s}, \mathrm{p}}=\sum_{\mathrm{i}=1}^{N} n_{\mathrm{i}} s_{\mathrm{i}}+\left[\left(n_{\left(\mathrm{Li}_{2} \mathrm{O}\right)} n_{\left(\mathrm{B}_{2} \mathrm{O}_{3}\right)}\right)\left(s_{\left(\mathrm{Li}_{2} \mathrm{O} * \mathrm{~B}_{2} \mathrm{O}_{3}\right)}\right)\right]
$$

where $T_{\mathrm{s}, \mathrm{p}}$ is the predicted $T_{\mathrm{s}}$ value for a given glass, $n_{\mathrm{i}}$ and $s_{\mathrm{i}}$ are the $i$-th component mass fractions in glass and model coefficients, respectively, and $\mathrm{N}$ is the number of components in the model (13).

In order to validate the model, a method was applied that has been used previously, as described by Vienna et al. [138]. Here, the data was sorted based on $T_{\mathrm{s}, \mathrm{p}}$ values, each glass was numbered sequentially $1,2,3,4,5,1,2, \ldots$ and then sorted by number, separating the data into 5 subsets of 117 glasses from the full dataset of 585 glasses. Then, the same model form, using the same components, was run for each individual subset and a new set of these $s_{\mathrm{i}}$ coefficients was generated for each subset of $80 \%$ of the data. The models thus fit were used to calculate a subset validation $R^{2}$ value $\left(R_{\mathrm{V}}^{2}\right)$ for each $20 \%$ data 
set not used to fit the model (not shown). Only 5 coefficients had \%RSD (relative standard deviation) > 15: $\mathrm{F}\left(41^{\circ} \mathrm{C}\right), \mathrm{K}_{2} \mathrm{O}\left(37^{\circ} \mathrm{C}\right), \mathrm{MgO}\left(26^{\circ} \mathrm{C}\right), \mathrm{Na}_{2} \mathrm{O}\left(103^{\circ} \mathrm{C}\right)$, and $\mathrm{B}_{2} \mathrm{O}_{3} * \mathrm{Li}_{2} \mathrm{O}\left(29^{\circ} \mathrm{C}\right)$, some of which were likely just due to few glasses being included in the subsets with some of these minor components.

The full set of data, including the predicted-vs-measured values for all the NBS-\# glass binders and P57, are plotted in Figure 20. Here, it can be seen that the model predicts fairly well for all of the NBS-\# glasses, but not very well for P57. This large overprediction for P57 of $134.9^{\circ} \mathrm{C}$ could be due to the fact that this glass was one of the more extreme compositions with very high $\mathrm{SiO}_{2}(66.86$ mass $\%)$ and moderately high $\mathrm{B}_{2} \mathrm{O}_{3}(18.84$ mass \%) and likely near the range of confidence for the model. The difference between predicted and measured $\left(T_{\mathrm{s}, \mathrm{m}}\right)$ data, i.e., $T_{\mathrm{s}, \mathrm{p}}-T_{\mathrm{s}, \mathrm{m}}$, for NBS-2, NBS-3, NBS-4, NBS-5, and NBS-6, were $7.9,15.1,25.4,-2.2$, and $1.1^{\circ} \mathrm{C}$, respectively.

\section{Conclusions}

Five new glass binders, NBS-2, NBS-3, NBS-4, NBS-5, and NBS-6 were formulated for use in making glass-bonded sodalite advanced ceramic waste forms. Each glass was synthesized and then characterized using a variety of analytical techniques. Each of the NBS-\# glasses contained 20.17 mass\% $\mathrm{Na}_{2} \mathrm{O}$ to help drive chlorosodalite production. Additionally, the previous baseline glass, P57, was included in the characterization. The glasses were used as binders during fabrication of ceramic waste forms at a glass loading of 26 mass \% and a SOZ loading of 74 mass\% (which is a salt waste loading of 11 mass $\%$ ). This represents a roughly $40 \%$ increase in loading compared to the baseline ceramic waste form. In addition to this basic set of samples, several variables were changed to create new samples including other salt loadings $(8,12,14$ mass $\%)$, different sized precursor powders $(<74 \mu \mathrm{m}$, instead of the standard 74-250 $\mu \mathrm{m})$, different glass loadings (25, 52 mass $\%)$, and different crucible types (glassy carbon or alumina).

The NBS-\# glasses showed an improvement of higher sodalite yield for the CWFs, lower halite and amorphous phase fractions, and a closer-matched coefficient of thermal expansion to the sodalite measured for one of the ACWFs (ACWF-26N4-11). Matching the coefficients of thermal expansion 
between the glass and sodalite phases may result in less cracking in the final waste form and potentially lower thermal cycle times for the full-scale process. While the open porosities in the fired ceramic waste forms were lower for the samples made with the P57 glass (i.e., CWF-26P-11, $\phi_{\mathrm{a}}=32.6 \%$ ) than for those made with the NBS-\# binders (ACWF-26N\#-11 samples, $\phi_{\mathrm{a}}=37.3-44.9 \%$ ), all samples showed higher values than desired. Additional work is necessary to optimize process conditions to achieve nearly fulldensity waste forms. The work here demonstrates evidence for alkali exchange that occurs between the $\mathrm{Na}$ in the glass phase and the $\mathrm{Li} / \mathrm{K}$ in the salt phase where the Na preferentially incorporates into the sodalite phase and the $\mathrm{Li} / \mathrm{K}$ migrates from the $\mathrm{SOZ}$ phase to the glass phase during the heat-treatment process.

At an 8 mass $\%$ salt loading, the CWF made with the P57 binder glass (CWF-25P-8, $\phi_{a}=14.2$ vol\%) had lower porosity than the CWF made with NBS-4 glass (ACWF-26N4-8, $\phi_{a}=44.1 \mathrm{vol} \%$ ) at comparable glass loadings ( 25 vs 26 mass $\%$, respectively). However, the sodalite yields for CWF-25P-8 and ACWF-26N4-8 were 42.3 and 61.5 mass\%, respectively. At the 11 mass\% salt loadings, the NBS-\# glasses show higher sodalite yield than the sample made with the P57 glass (CWF-26P-11) where all samples had porosities higher than desired. The samples with salt loadings $>11$ mass $\%$ showed high sodalite yields but with increased halite fractions and comparable porosities; these experiments were pushing the limit of salt loading and demonstrate that salt added above a critical limit does not incorporate into the sodalite phase. While the physical properties of CWFs made with the NBS-\# glasses at 11 mass\% salt loadings were all quite similar, the CWF made with the NBS-4 binder glass performed best in chemical durability tests (not reported here - see [23]); thus, the NBS-4 glass would be the best choice for future studies from that perspective.

Bateman et al. [22] defined the ideal properties of a binder glass for making glass-bonded sodalite ceramic waste forms. The goal of the current work was to develop new binder glasses that could meet as many of these requirements as possible. According to Bateman et al., the binder should

1) have a $T_{\mathrm{s}}$ that is $<750{ }^{\circ} \mathrm{C}$ where ideal processing temperatures are in the range of $750-925^{\circ} \mathrm{C}$,

2) have a long working range so it does not drain through the product during heat-treatment, 
3) wet the salt-occluded zeolite (SOZ) and sodalite mixture,

4) have a coefficient of thermal expansion (CTE) that is similar to that of the SOZ/sodalite mixture to minimize, or even prevent, cracking during cool-down,

5) be free-flowing,

6) allow for packing of $40-45 \%$ of theoretical density,

7) densify uniformly during heating, and

8) produce non-friable waste form surfaces.

Following this study, some extra attributes should be added including that the glass binder should also:

9) provide additional $\mathrm{Na}_{2} \mathrm{O}$ for incorporation into the sodalite structure which immobilizes the long-lived halogen radionuclides, i.e., ${ }^{129} \mathrm{I}\left(t_{1 / 2}=1.57 \times 10^{7} \mathrm{yr}\right)$ and ${ }^{36} \mathrm{Cl}\left(t_{1 / 2}=3.01 \times 10^{5} \mathrm{yr}\right)$, 10) be able to structurally accommodate the fission products that do not incorporate into the sodalite phase, e.g., actinides, lanthanides, alkaline earths, and transition metals, 11) form a chemically durable glass upon ion exchange with the SOZ phase, and 12) be effective enough to provide these added benefits at a minimal frit loading because adding any form of glass binder to the SOZ increases the overall volume of the waste form, reducing the volumetric waste loading (same waste mass in a larger volume).

In addition to the experimental work, a model was developed to predict the $T_{\mathrm{s}}$ values of the glasses made in the current study as well as prospective silicate glasses for future waste forms. The value of $T_{\mathrm{s}}$ for a glass is one of the critical parameters for making sure that the binder has an adequately low viscosity at the temperatures where the glass-SOZ interactions take place. If the $T_{\mathrm{s}}$ value of a prospective binder glass is too high, the alkali exchange reactions and consolidation (to close the porosity) will require more time at the processing temperature, leading to a more inefficient process or an unsuccessful consolidation. The model presented here predicted all 5 of the NBS-\# glasses fairly well where the difference between predicted and measured $\left(T_{\mathrm{s}, \text { meas }}\right)$ data, i.e., $T_{\mathrm{s}, \text { pred }}-T_{\mathrm{s} \text {, meas }}$, for NBS-2, NBS-3, NBS-4, NBS-5, and NBS-6 were $7.9,15.1,25.4,-2.2$, and $1.1^{\circ} \mathrm{C}$, respectively. The P57 glass was highly 
overpredicted at $134.9{ }^{\circ} \mathrm{C}$ over the measured value. This model shows promise for predicting $T_{\mathrm{s}}$ values of future binder glasses.

\section{Acknowledgements}

Pacific Northwest National Laboratory (PNNL) is operated by Battelle Memorial Institute for the DOE under contract DE-AC05-76RL01830. This work was supported by the DOE Office of Nuclear Energy's (DOE-NE) Nuclear Technology Research and Development Program under the Materials Recovery and Waste Form Development Campaign. The authors thank Kimberly Gray of DOE-NE for support and programmatic guidance. A portion of the research was performed using capabilities in the William R. Wiley Environmental Molecular Sciences Laboratory, a national scientific user facility sponsored by DOE's Office of Biological and Environmental Research and located at PNNL, under user proposal number 48708. The authors thank William Ebert and Charmayne Lonergan for helpful comments on the paper, Clyde Chamberlin, Anthony Guzman, and Shelley Carlson for helping prepare the specimens for analyses, and Kent Parker for help collecting the specific surface area measurements.

\section{References}

[1] S.X. Li, T.A. Johnson, B.R. Westphal, K.M. Goff, R.W. Benedict. 2005. Proc. of GLOBAL 2005, pp. 487.

[2] L.S. Hersh, O.J. Kleppa, J. Chem. Phys. 42 (4) (1965) 1309-1322.

[3] B.F. Markov, T.A. Tishura, A.N. Budarina, Rev. Roum. Chim. 20 (5) (1975) 597-602.

[4] A. Nakayoshi, S. Kitawaki, M. Fukushima, T. Murakami, M. Kurata, J. Nucl. Mater. 441 (1-3) (2013) 468-472.

[5] J.P. Ackerman, T.R. Johnson, L.S.H. Chow, E.L. Carls, W.H. Hannum, J.J. Laidler, Prog. Nucl. Energy 31 (1-2) (1997) 141-154.

[6] S. Priebe, K.J. Bateman, Nucl. Technol. 162 (2) (2008) 199-207.

[7] J.M. Juoi, M.I. Ojovan, W.E. Lee, J. Nucl. Mater. 372 (2-3) (2008) 358-366. 
[8] M.I. Ojovan, J.M. Juoi, A.R. Boccaccini, W.E. Lee. 2008. Proc. of MRS Proceedings, Vol. 1107. Cambridge University Press, 10.1557/PROC-1107-245.

[9] J.M. Juoi, M.I. Ojovan, Glass Technol. - Eur. J. Glass Sci. Technol. A 48 (3) (2007) 124-129.

[10] W.C. Lepry, B.J. Riley, J.V. Crum, C.P. Rodriguez, D.A. Pierce, J. Nucl. Mater. 442 (1-3) (2013) 350-359.

[11] B.J. Riley, W.C. Lepry, J.V. Crum, J. Nucl. Mater. 468 (2016) 140-146.

[12] B.J. Riley, D.A. Pierce, S.M. Frank, J. Matyáš, C.A. Burns, J. Nucl. Mater. 459 (2015) 313-322.

[13] B.J. Riley, J.V. Crum, J. Matyáš, J.S. McCloy, W.C. Lepry, J. Am. Ceram. Soc. 95 (10) (2012) $3115-3123$

[14] E.R. Vance, J. Davis, K. Olufson, I. Chironi, I. Karatchevtseva, I. Farnan, J. Nucl. Mater. 420 (1-3) (2012) 396-404.

[15] I.W. Donald, B.L. Metcalfe, S.K. Fong, L.A. Gerrard, D.M. Strachan, R.D. Scheele, J. Nucl. Mater. 361 (1) (2007) 78-93.

[16] S.K. Fong, I.W. Donald, B.L. Metcalfe, J. Alloy Comp. 444-445 (2007) 424-428.

[17] T.L. Moschetti, W. Sinkler, T. DiSanto, M.H. Noy, A.R. Warren, D. Cummings, S.G. Johnson, K.M. Goff, K.J. Bateman, S.F. Frank. 2000. Proc. of Mater. Res. Soc., Vol. 608, pp. 577-582, Ed. D. W. Shoesmith and R. W. Smith. Materials Research Society, Warrendale, PA.

[18] W. Sinkler, T.P. O’Holleran, S.F. Frank, M.K. Richmann, S.G. Johnson. 2000. Proc. of Mater. Res. Soc., Vol. 608, pp. 423-429, Ed. R. W. Smith and D. W. Shoesmith. Materials Research Society, Warrendale, PA.

[19] T.L. Moschetti, T.P. O’Holleran, S.F. Frank, S.G. Johnson, D.W. Esh, K.M. Goff. 2000. Proc. of Ceram. Trans., Vol. 107, pp. 509-516, Ed. G. T. Chandler and X. Feng. American Ceramic Society, Westerville, $\mathrm{OH}$.

[20] W. Sinkler, D.W. Esh, T.P. O'Holleran, S.F. Frank, T.L. Moschetti, K.M. Goff, S.G. Johnson. 1999. Proc. of Ceram. Trans., Vol. 107, pp. 233-240, Ed. G. T. Chandler and X. Feng. American Ceramic Society, Westerville, $\mathrm{OH}$. 
[21] R.D. Shannon, Acta Cryst. A 32 (1976) 751-767.

[22] K.J. Bateman, C.J. Knight, C. Solbrig, W. 2007. Current Status of Ceramic Waste Form Development. INL/INT-06-11736. Idaho National Laboratory, Idaho Falls, ID.

[23] W.L. Ebert, C.T. Snyder. 2015. Corrosion Tests with Waste Forms Developed for EChem Salt Wastes. FCRD-MRWFD-2015-000145. Argonne National Laboratory, Lemont, IL.

[24] M.R. Gilbert. 2015. Proc. of Mater. Res. Soc., Vol. 1744, Ed. S. Gin, R. Jubin, J. Matyáš, and E. R. Vance. Materials Research Society, Warrendale, PA, http://dx.doi.org/10.1557/opl.2015.694.

[25] J. Vienna, J. Luey, P. Hrma, H. Li, D. Smith, R. Scheele. 1998. Proc. of the Ceram. Trans., Vol. 93, pp. 399-407, Ed. J. C. Marra and G. T. Chandler. American Ceramic Society, Westerville, OH.

[26] J.K. Luey, R.D. Scheele, H. Li, H.L. Wigent. 1999. Evaluation of a Vitrification processing Step for Rocky Flats Incinerator Ash. PNNL-12102. Pacific Northwest National Laboratory, Richland, WA.

[27] J.D. Vienna, P. Hrma, M.J. Schweiger, M.H. Langowski. 1996. Proc. of the Ceram. Trans., Vol. 72, pp. 307-316, Ed. V. Jain and D. K. Peeler. American Ceramic Society, Westerville, OH.

[28] X. Feng, P.R. Hrma, J.H. Westsik Jr., N.R. Brown, M.J. Schweiger, H. Li, J.D. Vienna, G. Chen, G.F. Piepel, D.E. Smith, B.P. McGrail, S.E. Palmer, D. Kim, Y. Peng, W.K. Hahn, A.J. Bakel, W.L. Ebert, D.K. Peeler, C. Chang. 1996. Glass Optimization for Vitrification of Hanford Site Low-Level Tank Waste. PNNL-10918. Pacific Northwest National Laboratory, Richland, WA.

[29] M.B. Volf, Chemical Approach to Glass. New York: Elsevier (1984).

[30] J. Zarzycki, Glasses and the Vitreous State, pp. 266-267. Cambridge: Cambridge University Press (1982).

[31] C. Cailleteau, F. Angeli, F. Devreux, S. Gin, J. Jestin, P. Jollivet, O. Spalla, Nature 7 (12) (2008) 978-983.

[32] J.D. Vienna, D. Kim, P. Hrma. 2002. Database and Interim Glass Property Models for Hanford HLW and LAW Glasses. PNNL-14060. Pacific Northwest National Laboratory, Richland, WA. 
[33] P. Hrma, G.F. Piepel, M.J. Schweiger, D.E. Smith, D.-S. Kim, P.E. Redgate, J.D. Vienna, C.A. LoPresti, D.B. Simpson, D.K. Peeler, M.H. Langowski. 1994. Property/Composition Relationships for Hanford High-Level Waste Glasses Melting at $1150^{\circ} \mathrm{C}$. PNL-10359. Pacific Northwest National Laboratory, Richland, WA.

[34] R.G.C. Beerkens, J. Am. Ceram. Soc. 86 (11) (2003) 1893-1899.

[35] D.S. Kim, P. Hrma, S.E. Palmer, D.E. Smith, M.J. Schweiger. 1995. Proc. of the Ceram. Trans., Vol. 61, pp. 531-538. American Ceramic Society.

[36] C.M.B. Henderson, D. Taylor, Physics and Chemistry of Minerals 2 (1978) 337-347.

[37] P. Hrma, G.F. Piepel, J.D. Vienna, P.E. Redgate, M.J. Schweiger, D.E. Smith. 1995. Proc. of Ceram. Trans., Vol. 61, pp. 497-504, Ed. V. Jain and R. Palmer. American Ceramic Society, Westerville, $\mathrm{OH}$.

[38] J.D. Vienna, D.S. Kim, P. Hrma. 2003. Proc. of Ceram. Trans., Vol. 143, pp. 151-157, Ed. S. K. Sundaram, D. R. Spearing, and J. D. Vienna. American Ceramic Society, Westerville, OH.

[39] X. Feng, M.J. Schweiger, P. Hrma, S.E. Palmer, D.E. Smith, D. Kim, M. Gong, J.H. Westsik Jr. 1995. Preliminary PCT Data on Glass Formulations Developed for Hanford Site Low-Level Wastes. PNL-10827, UC-721. Pacific Northwest National Laboratory, Richland, WA.

[40] ASTM C 1285-08, ASTM, American Society for Testing and Materials International, ASTM International Book of Standards Volume 12.01, West Conshohocken, PA, 2008.

[41] ASTM C 1662-10, ASTM, American Society for Testing and Materials International, ASTM International Book of Standards Volume 12.01, West Conshohocken, PA, 2010.

[42] T.P. O’Holleran. 1999. Ceramic Waste Form Intergranular Glass Composition. NT-NWM-(TO)-99010. Argonne National Laboratory-West, Idaho Falls, ID.

[43] SRM 732, Standard Reference Material 732, Single Crystal Sapphire - Thermal Expansion, National Institute for Standards and Technology, Gaithersburg, MD, 1977.

[44] SRM 674b, X-Ray Powder Diffraction Intensity Set (Quantitative Powder Diffraction Standard), National Institute for Standards and Technology, Gaithersburg, MD, 2012. 
[45] R.W. Cheary, A.A. Coelho, J.P. Cline, J. Res. Natl. Inst. Stand. Technol. 109 (1) (2004) 1-25.

[46] R.K. Kirby, Int. J. Thermophys. 12 (4) (1991) 679-685.

[47] Z. Wang, J. Liu, Y. Zhou, J.J. Neeway, D.K. Schreiber, J.V. Crum, J.V. Ryan, X.-L. Wang, F. Wang, Z. Zhu, Surf. Interface Anal. 48 (3) (2016) 1392-1401.

[48] K. Thompson, D. Lawrence, D.J. Larson, J.D. Olson, T.F. Kelly, K.B. Gorman, Ultramicroscopy 107 (2-3) (2007) 131-139.

[49] S.W. Stratton, Standard density and volumetric tables, $6^{\text {th }}$ ed. Washington: Government Printing Office (1924)

[50] D.J. Lacks, R.G. Gordon, Phys. Rev. B 48 (5) (1993) 2889-2908.

[51] H.L. Johnston, D.A. Hutchison, Phys. Rev. 62 (1942) 32-36.

[52] I. Hassan, S.M. Antao, J.B. Parise, Am. Mineral. 89 (2004) 359-364.

[53] G.O. Siqueira, É.G. Gravina, J.A.L.C. Resende, N.G. Fernandes, Am. Mineral. 24 (2009) 41-43.

[54] S. Brunauer, P.H. Emmett, E. Teller, J. Am. Chem. Soc. 60 (2) (1938) 309-319.

[55] B.J. Riley, J.S. McCloy, J.V. Crum, W.C. Lepry, C.P. Rodriguez, C.F. Windisch Jr., J. Matyáš, M.P. Westman, B.T. Rieck, J.B. Lang, M.J. Olszta, D.A. Pierce. 2014. Alternative Electrochemical Salt Waste Forms, Summary of FY11-FY12 Results. FCRD-SWF-2013-000025, Rev. 1, PNNL22034. Pacific Northwest National Laboratory, Richland, WA.

[56] E. Maddrell, A. Gandy, M. Stennett, J. Nucl. Mater. 449 (1-3) (2014) 168-172.

[57] M.F. Simpson, K.M. Goff, S.G. Johnson, K.J. Bateman, T.J. Battisti, K.L. Toews, S.F. Frank, T.L. Moschetti, T.P. O'Holleran, Nucl. Technol. 134 (3) (2001) 263-277.

[58] W.L. Ebert, N.L. Dietz, D.E. Janney. 2005. Effects of Heat-Treatment and Formulation on the Phase Composition and Chemical Durability of the EBR II Ceramic Waste Form. ANL-05/32. Argonne National Laboratory, Lemont, IL.

[59] W.L. Ebert. 2005. Testing to evaluate the suitability of waste forms developed for electrometallurgically-treated spent sodium-bonded nuclear fuel for disposal in the Yucca Mountain repository. ANL-05/43. Argonne National Laboratory, Argonne, IL. 
[60] M.F. Simpson. 2012. Developments of Spent Nuclear Fuel Pyroprocessing Technology at Idaho National Laboratory. INL/EXT-12-25124. Idaho National Laboratory, Idaho Falls, ID.

[61] K. Kadono, H. Tanaka, Compositional dependence of the precipitation of crystallites in copper(I) halide-doped glasses, pp. 223-227. In Science and Technology of New Glasses. Edited by S. Sakka and N. Soga, Tokyo, 1991.

[62] A. Tomasi, P. Scardi, F. Branda, A. Costantini, J. Mater. Sci. Lett. 12 (18) (1993) 1416-1419.

[63] O.A. Al-Harbi, Glass Technol.: Eur. J. Glass Sci. Technol. A. 48 (1) (2007) 35-40.

[64] F. Andreola, L. Barbieri, A. Corradi, I. Lancellotti, J. Europ. Ceram. Soc. 27 (2-3) (2007) 1623-1629.

[65] E.E. Assem, J. Phys. D: Appl. Phys. 38 (6) (2005) 942-945.

[66] H. Darwish, Ceram. Silicaty 49 (3) (2005) 153-161.

[67] E.R. Vance, P.J. Hayward, I.M. George, Phys. Chem. Glasses 27 (2) (1986) 107-113.

[68] F. Smeacetto, M. Salvo, M. Ferraris, V. Casalegno, P. Asinari, J. Europ. Ceram. Soc. 28 (3) (2008) 611-616.

[69] D. Giordano, A.R.L. Nichols, D.B. Dingwell, J. Volcan. Geotherm. Res. 142 (1-2) (2005) 105-118.

[70] E.M.A. Hamzawy, E.M. El-Meliegy, Ceram. Intern. 33 (2) (2007) 227-231.

[71] E.M.A. Hamzawy, C. Leonelli, Glass Technol. 46 (3) (2005) 281-286.

[72] M.H. Idris, G.A. Khater, Phys. Chem. Glasses 45 (2) (2004) 141-145.

[73] J. Yang, D. Zhang, J. Hou, B. He, B. Xiao, Ceram. Int. 34 (1) (2008) 125-130.

[74] K. Kata, I. Yashui, J. Ceram. Soc. Jpn 97 (3) (1989) 314-320.

[75] G.A. Khater, M.H. Idris, Ceram. Intern. 33 (2) (2007) 233-238.

[76] N. Lagakos, J.A. Bucaro, Appl. Opt. 20 (15) (1981) 2716-2720.

[77] A.X. Lu, Z.B. Ke, Z.H. Xiao, X.F. Zhang, X.Y. Li, J. Non-Cryst. Solids 353 (28) (2007) 2692-2697.

[78] A.A. Omar, A.W.A. El-Shennawi, G.A. Khater, Brit. Ceram. Trans .J. 90 (1991) 179-183.

[79] B. Ryu, H. Sakamura, I. Yasui, J. Ceram. Soc. Jpn 101 (5) (1993) 579-582.

[80] S. Sakka, M. Tashiro, J. Ceram. Assoc. Jpn 69 (3) (1961) 67-74.

[81] S.M. Salman, S.N. Salama, H. Darwish, Glass Technol. 43C (2002) 222-228. 
[82] B.E. Yekta, V.K. Marghussian, J. Mater. Sci. 36 (2) (2001) 477-483.

[83] G.F. Brewster, R.A. Weidel, "Barium flint ophthalmic segment glass," patent number US3481751(A), 1969.

[84] Y. Chen, D. Zhu, "Crown glass in use for discharge lamp in low pressure," patent number CN1600720, 2005.

[85] J. Chiba, "Sealing Glass Composition," patent number JPH03275531, 1991.

[86] J.H. Connelly, "Glass for projection cathode ray tube faceplate," patent number US4830990(A), 1988.

[87] G. Electric, "Improvements in luminous electric discharge lamps," patent number GB432614(A), 1935.

[88] G.J. Fine, "Fluoroborosilicate glass and clad article," patent number US4973565(A), 1989.

[89] T. Futagami, Y. Takagi, "Glass for fluorescent lamp, glass tube for fluorescent lamp and fluorescent lamp," patent number JP2002137935(A), 2000.

[90] D.C. Greenspan, "Glass compositions for bonding to alloys," patent number EP0154513, 1984.

[91] M.J. Hartmann, K. Lo Kuang-hsin, D.A. Nolan, "Electrically insulating body," patent number US4699831(A), 1987.

[92] M. Higashida, A. Sawai, "Glass for adhering ferrite," patent number JP7061836, 1995.

[93] H. Masuda, S. Akira, "Glass composition for low-temperature fired substrate and glass ceramics using the same," patent number JP2004026529(A), 2004.

[94] Y. Ishida, K. Ooka, H. Takashio, H. Murata, Y. Minoura, K. Takagi, "Composite materials of tempered glass insulator for use in electric power transmission lines," patent number DE2047661(A1), 1971.

[95] M. Ishihara, H. Takahashi, "Glass composition having low melting point," patent number JPS59162145(A), 1984.

[96] M. Kasori, H. Imagawa, H. Maki, K. Yagi, O. Kokubo, "Clading glass for optical fiber," patent number US4768859(A), 1988. 
[97] K. Kato, T. Kawamura, N. Inoko, H. Norizuki, "Lead-free glass flux and China-painting material containing the flux," patent number JP2004067455(A), 2004.

[98] T. Kawaguchi, "Glass composition for decoration and crystallized glass substrate for decoration," patent number JP2007039294(A), 2007.

[99] T. Kawaguchi, A. Hayamizu, "Glass for fluorescent lighting," patent number JPS5860638, 1983.

[100] T. Kawamura, H. Hayashi, N. Inoko, "Lead-free glass flux and ching hand-painting material containing the same," patent number JP2003238200(A), 2003.

[101] K. Kawashima, K. Ikada, "Lighting glass composition, fluorescent lamp and lighting fittings," patent number JP2005213129(A), 2005.

[102] K. Kawashima, O. Shirai, "Tubular bulb product," patent number JP2002358925(A), 2002.

[103] K. Kondo, T. Kurachi, M. Okuyama, "Glaze composition for ceramic base board," patent number JPS60145932(A), 1985.

[104] B. Merigaud, M. Claus, "Non-toxic glass frits," patent number EP0294502(A1), 1988.

[105] G.A. Merkel, D.F. Thompson, L.S. TRajnik, D.S. Weiss, "Transparent lead-free glazes," patent number EP0565880(A2), 1993.

[106] Y. Minora, patent number JPS5171314(A), 1976.

[107] J.M. Nigrin, "Low temperature lead and cadmium-free frits," patent number US4590171(A), 1986.

[108] J.M. Nigrin, P.L. Rose, J.L. Stempin, D.R. Wexell, "Transparent lead- and cadmium-free glazes," patent number EP0522263(A1), 1993.

[109] T. Nishida, T. Tanaka, "Conductive vanadate glass and manufacture method hereof," patent number JP2004002181(A), 2004.

[110] H. Onoda, H. Usui, "Lead-free glass, composition for electronic circuit board, and electronic circuit board," patent number JP2004244271(A), 2004.

[111] K. Otaki, K. Yoda, N. Baba, T. Harada, "Glass composition for producing inorganic fiber, production method therefor and inorganic fiber moldeing thereof," patent number JP2003212596, 2003. 
[112] H. Oyama, T. Ariga, "Ultraviolet-absorbing glass for liquid crystal display illumination and glass tube," patent number JP2007039281(A), 2007.

[113] U. Peuchert, C. Kunert, R. Bartsch, "Borosilicate glass with high chemical resistance and use thereof," patent number EP1303461(A1), 2003.

[114] E. Rodek, W. Kiefer, F. Siebers, "Lead-and cadmium-free glass composition for glazing, enameling, and decorating," patent number GB2263478(A), 1993.

[115] Y. Sakakibara, "Phosphor lamp used in an illuminating body comprises a light-permeable glass tube containing sodium oxide, potassium oxide, lithium oxide and antimony oxide, and a base with an electrode arranged at each end of the tube," patent number DE10108970(A1), 2001.

[116] O. Sakamoto, A. Hayamizu, "Glass for circular fluorescent lamp," patent number JPS5751150, 1982.

[117] G.E. Sakoske, G. Tunker, "High durability low temperature lead-free glass and enamel compositions with low boron content," patent number US2002004443(A1), 2002.

[118] R. Sawa, J. Abe, T. Atagi, M. Itou, T. Akai, M. Yamashita, "Glass composition for lamp, glass part for lamp, and process for producing lamp or glass composition for lamp," patent number WO2007007651, 2007.

[119] A. Sawai, M. Higashida, "Glass composition for adhesion," patent number JPH0455341, 1992.

[120] H. Sekine, T. Misuishi, H. Norizuki, S. Kamiya, "Leadless glass composition," patent number JPH08259258(A), 1996.

[121] T. Shimizu, N. Shimizu, S. Harada, "Board for additive circuits," patent number US4524098(A), 1985.

[122] N. Shindo, M. Kawahara, Y. Ota, "Glass powder and conductor paste containing the same," patent number JP2006089310(A), 2006.

[123] P.J. Smith, H.K. Mangat, "Cobalt glass compositions for coatings," patent number WO9509131(A1), 1995.

[124] Y. Takagi, M. Nakatani, "Glass for bulb," patent number JPS5460778(A), 1979. 
[125] H. Tosaki, H. Tanei, A. Ikegami, N. Sugishita, "Glass multilayer wiring board and method for its manufacture," patent number US4547625(A), 1985.

[126] S. Watanabe, M. Hirose, "Glass for ring-shaped fluorescent bulb," patent number JPS6046947(S), 1985.

[127] K. Yamanaka, Y. Douya, H. Usui, S. Otaki, T. Manabe, "Lead-free low melting point glass for formation of barrier rib and glass ceramic composition," patent number JP2001163635(A), 2001.

[128] M. Yamazaki, "Bonding glass for magnetic head," patent number JPS61247639(A), 1986.

[129] Y. Okawara, Y. Mansanobu, M. Ao, "Glass composition for magnetic head," patent number JPS6461330(A), 1989.

[130] H. Takahashi, M. Ishihara, "Low melting point glass composition," patent number JPS61295258(A), 1986.

[131] G. Lambert-Dusollier, "Contribution à l'étude de la transition vitreuse dans les verres silico sodocalciques recuits et trempes," Ph.D. Thesis, 1974.

[132] I.I. Kitaigorodskii, G.G. Sentyurin, Novye Neorganicheskie Materialy. AN SSSR: Moskva (1968).

[133] M.S. Nicolescu, S. Radicescu, D. Radu. 2007. Proc. of Proc. XXI ${ }^{\text {th }}$ Intern. Congr. on Glass, pp. T34.

[134] K. Kanagawa, patent number JP49006012, 1974.

[135] T. Kanbara, patent number JP48040812, 1973.

[136] Y. Kokubu, K. Sugaya, Y. Suzuki, patent number JP49008507, 1974.

[137] H. Takashio, patent number JP48034211, 1973.

[138] J.D. Vienna, D.-S. Kim, I.S. Muller, G.F. Piepel, A.A. Kruger, J. Am. Ceram. Soc. 97 (10) (2014) $3135-3142$ 


\section{Figures}

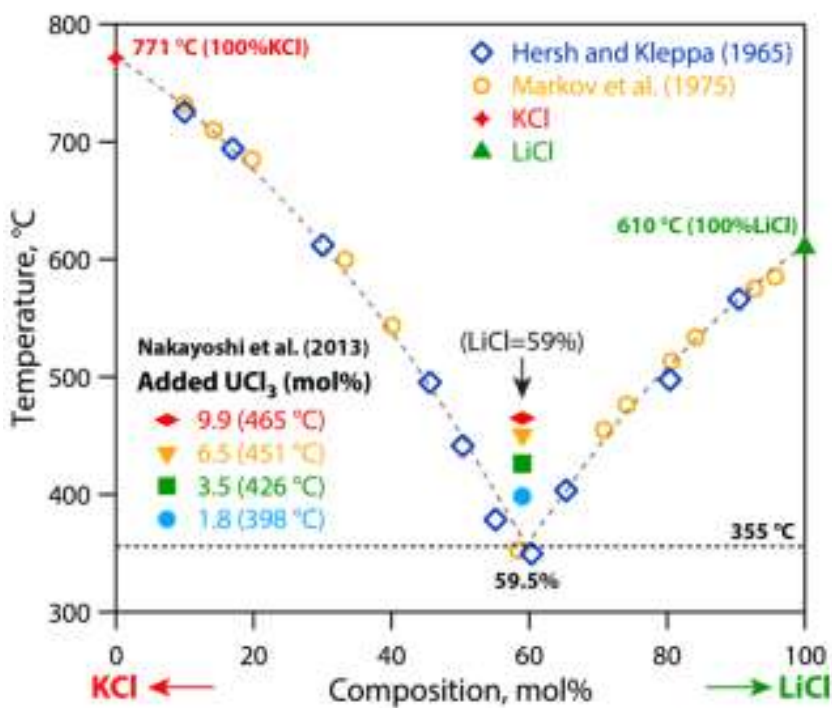

Figure 1. LiCl-KCl phase diagram from Hersh and Kleppa [2] and Markov et al. [3] with the eutectic temperature at $59.5 \mathrm{~mol} \% \mathrm{LiCl}$. In addition to this data are shown various loadings of $\mathrm{UCl}_{3}$ taken from Nakayoshi et al. [4].

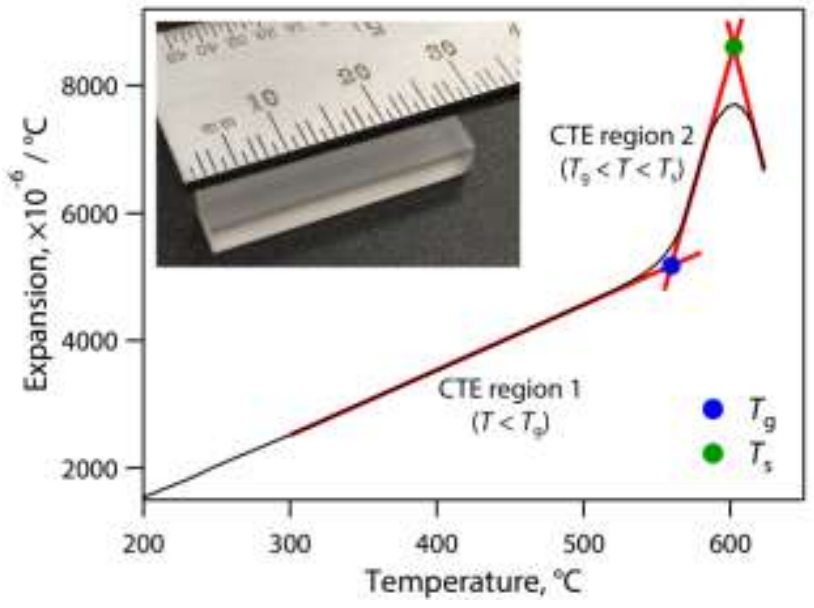

Figure 2. Expansion as a function of temperature for NBS-2 with a picture of the glass bar in the inset prior to the measurement as an example of a typical dataset and bar appearance. Also shown on the plot are the labels for CTE region $1\left(T<T_{\mathrm{g}}\right)$ and CTE region $2\left(T_{\mathrm{g}}<T<T_{\mathrm{s}}\right)$. 


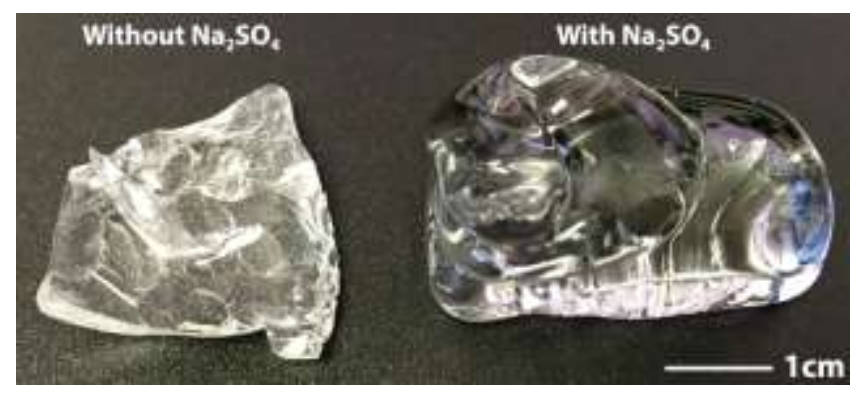

Figure 3. Visual comparison between the $\mathrm{P57}$ glass with and without $\mathrm{Na}_{2} \mathrm{SO}_{4}$.

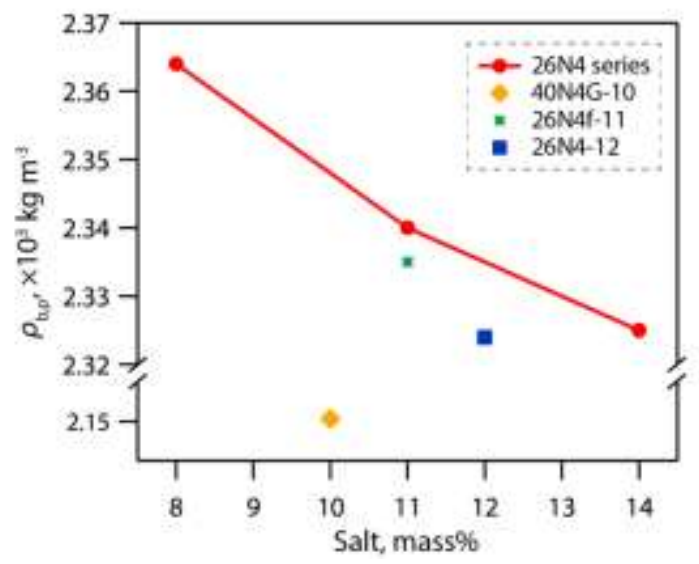

Figure 4. Bulk pycnometric density $\left(\rho_{\mathrm{b}, \mathrm{p}}\right)$ for the NBS-4 sample series. The red circles include samples ACWF-26N4-8, ACWF-26N4-11, and ACWF-26N4-14. 

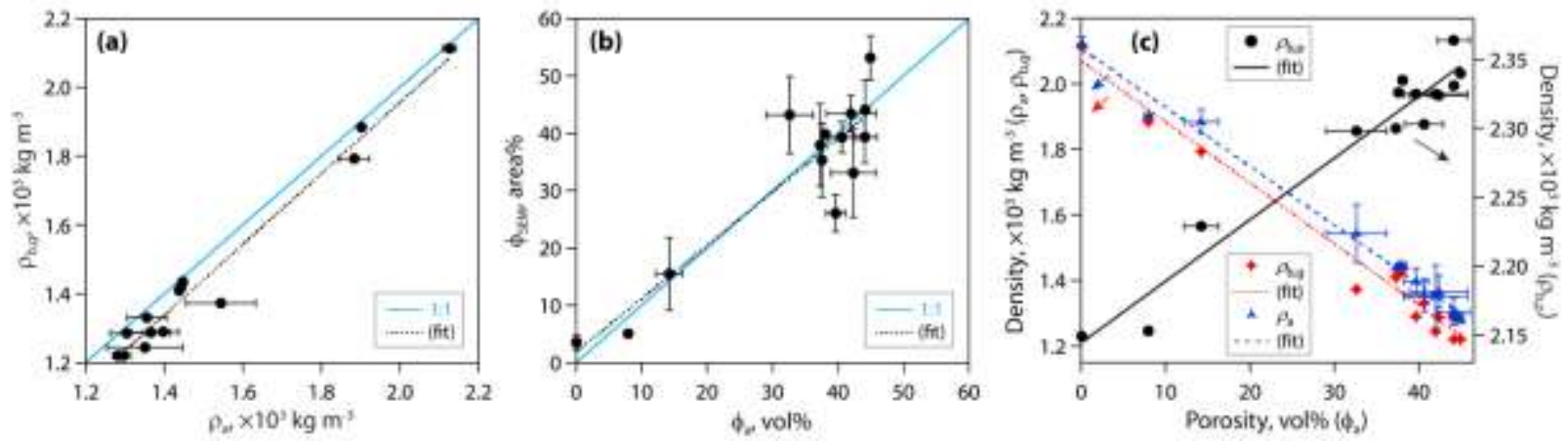

Figure 5. Density and porosity comparisons for all CWFs and ACWFs including (a) $\rho_{\mathrm{b}, \mathrm{p}}$ and $\rho_{\mathrm{a}}$, (b) $\phi_{\mathrm{a}}$ and $\phi_{\mathrm{SEM}}$, and (c) densities $\left(\rho_{\mathrm{a}}, \rho_{\mathrm{b}, \mathrm{g}}\right.$, and $\left.\rho_{\mathrm{b}, \mathrm{p}}\right)$ as a function of porosity $\left(\phi_{\mathrm{a}}\right)$. In (a) and (b), 1:1 trendlines are shown along with linear trendlines fit to each dataset.

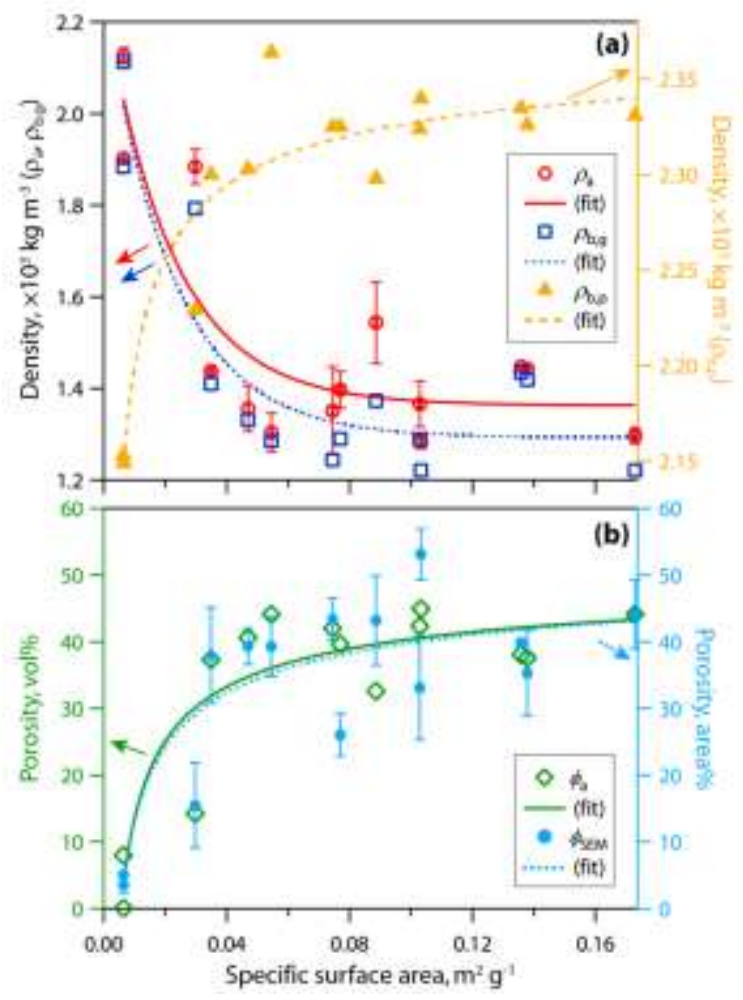

Figure 6. (a) Densities $\left(\rho_{\mathrm{a}}, \rho_{\mathrm{b}, \mathrm{g}}\right.$, and $\left.\rho_{\mathrm{b}, \mathrm{p}}\right)$ and (b) porosities $\left(\phi_{\mathrm{a}}\right.$ and $\left.\phi_{\mathrm{SEM}}\right)$ versus specific surface areas for all CWFs and ACWFs. 

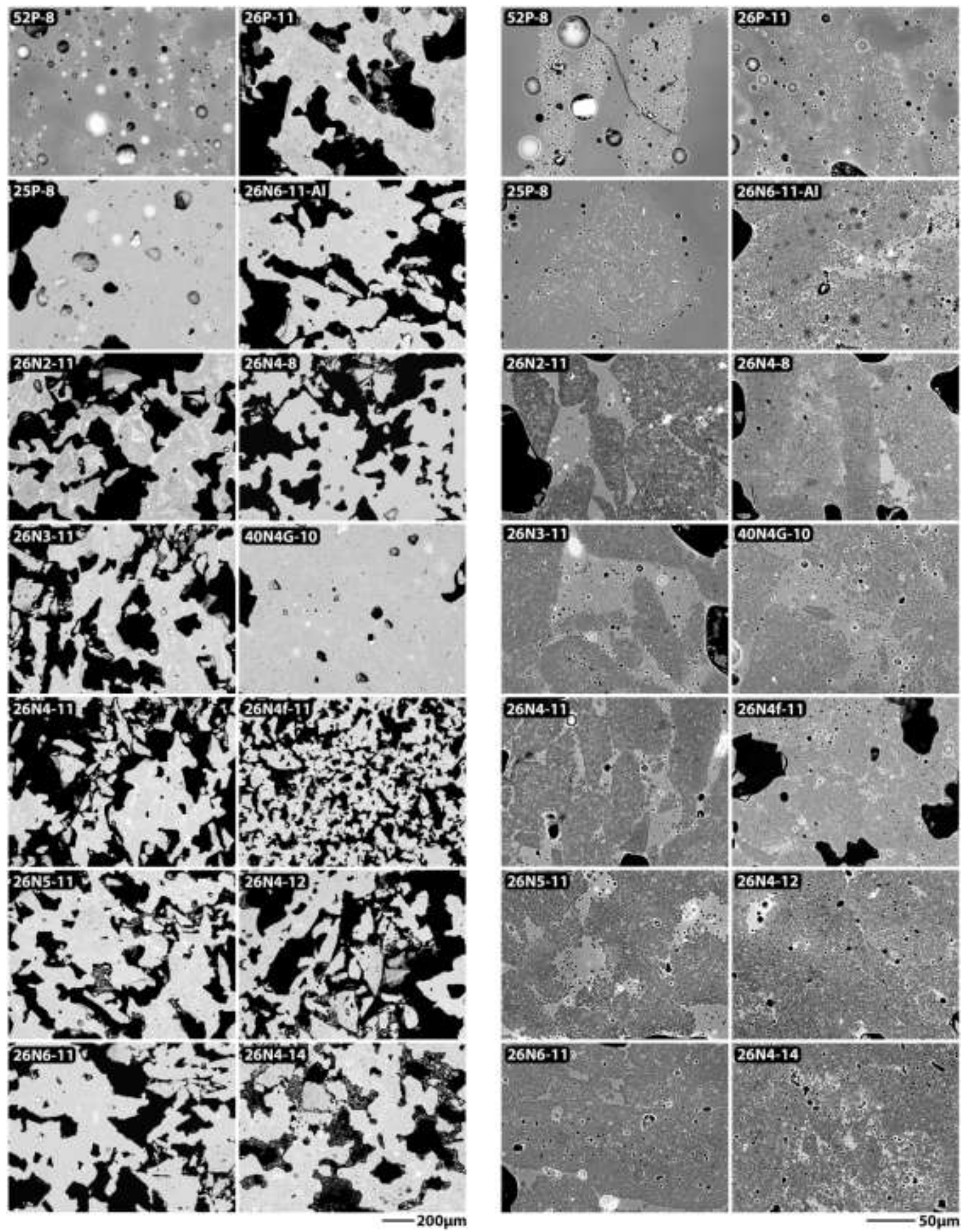

Figure 7. BSE-SEM micrographs at (two left columns) $85 \times$ and (two right columns) $500 \times$ magnifications showing the distribution of glassy regions and the sodalite domains. The black regions represent void spaces (open porosity) that were vacuum-impregnated with resin prior to polishing. 


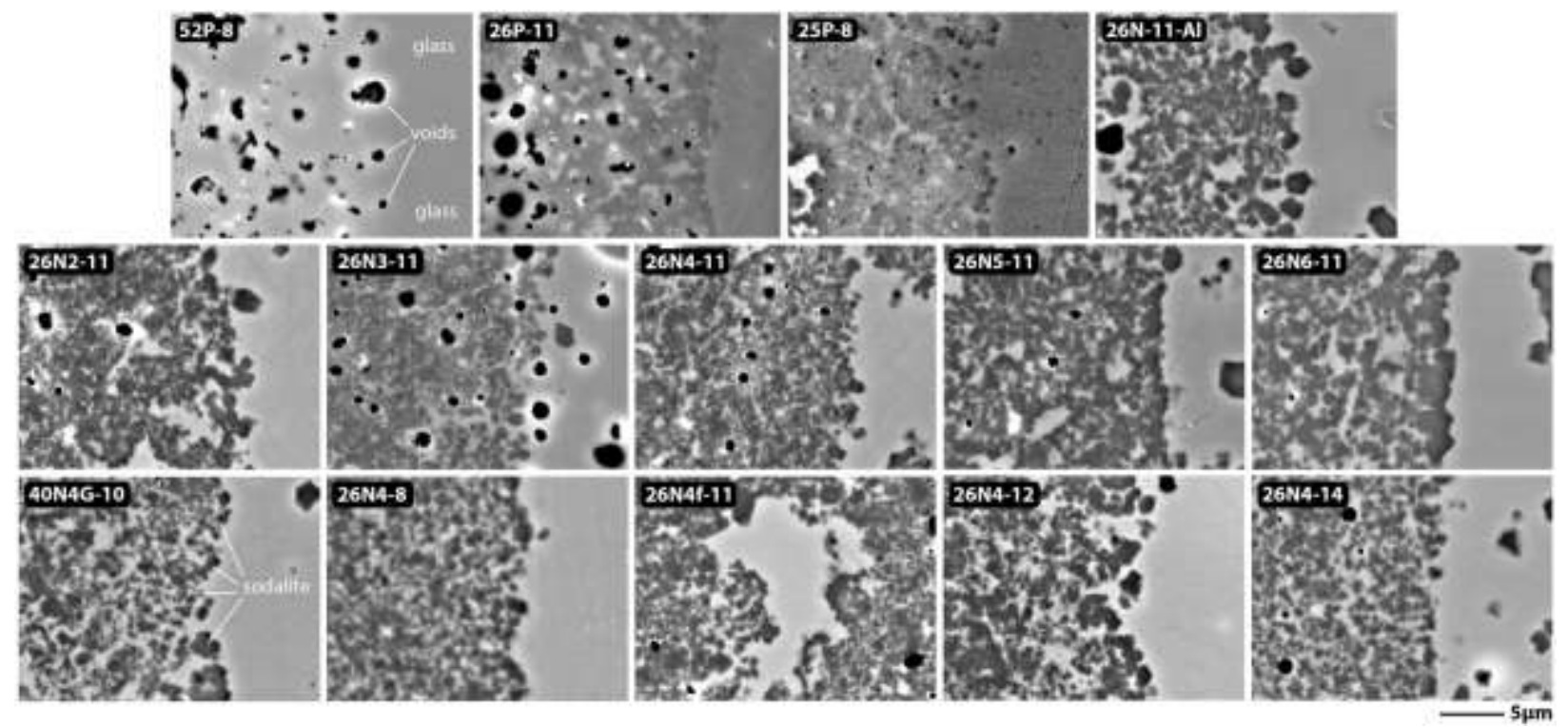

Figure 8. BSE-SEM micrographs at $5 \mathrm{k} \times$ magnification. The different phases (i.e., glass, voids, sodalite) are denoted by callouts. 


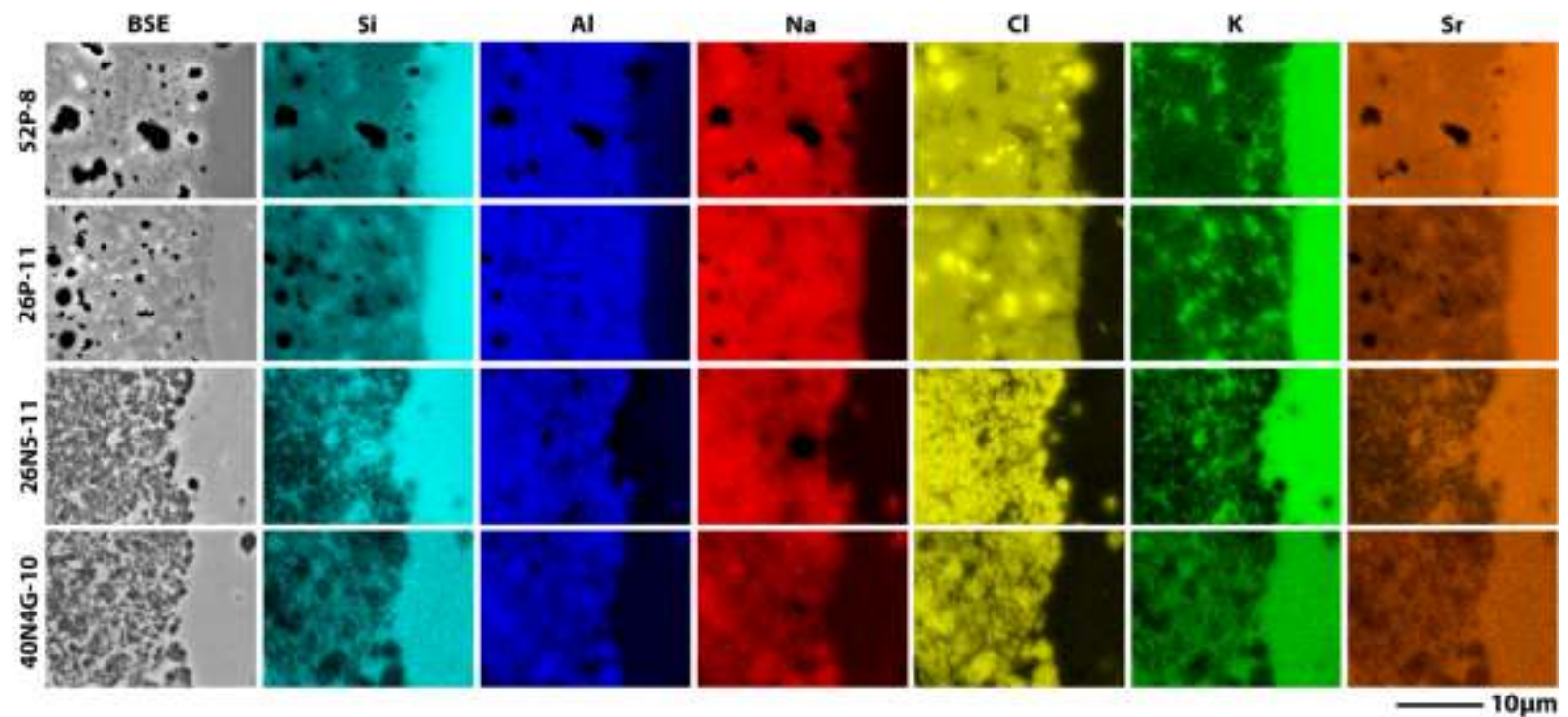

Figure 9. BSE-SEM micrographs and EDS elemental maps for CWF-52P-8, CWF-26P-11, ACWF-26N5-11, and ACWF-40N4G-10. 

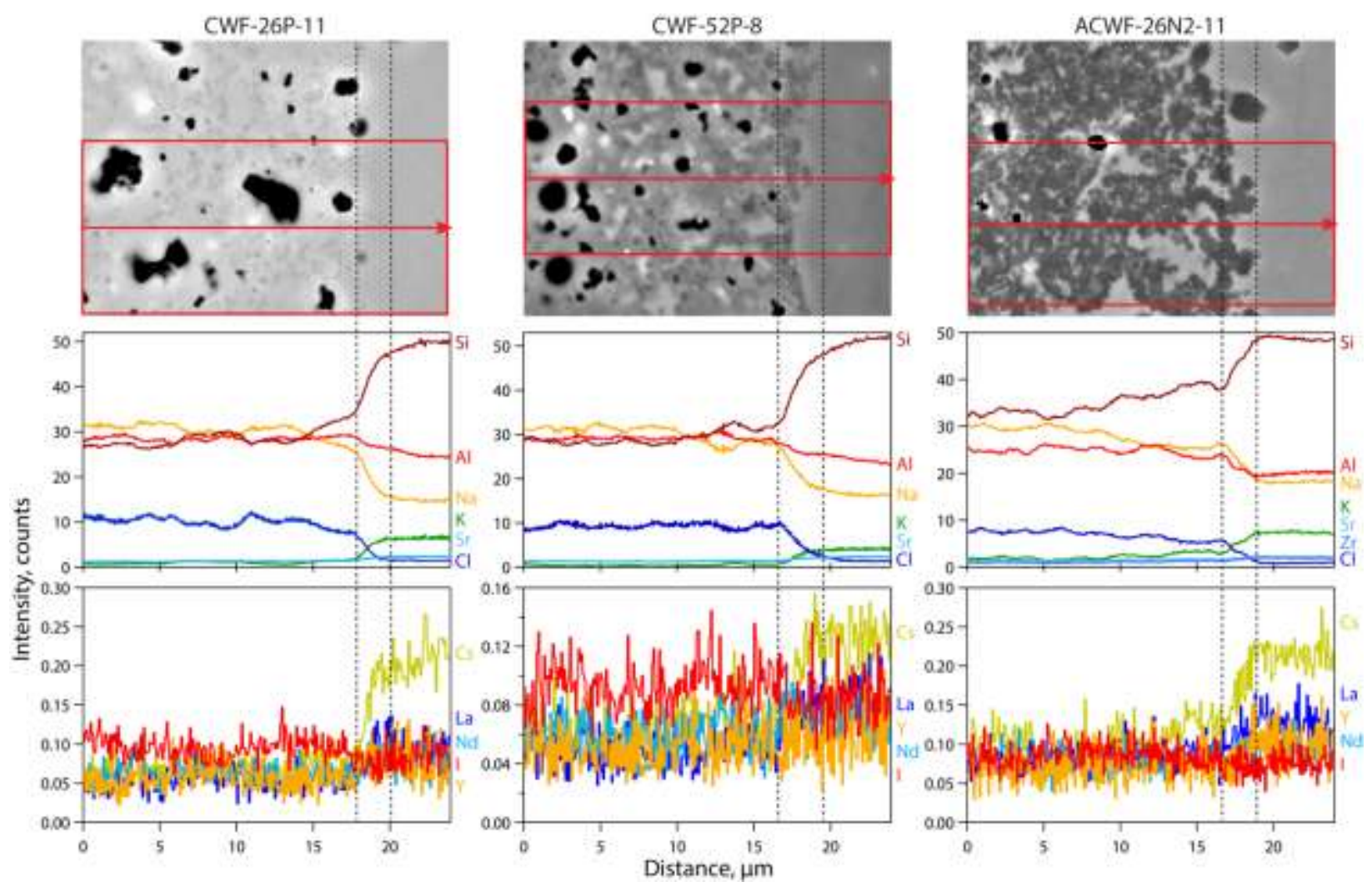

Figure 10. BSE-SEM micrographs and EDS linescans for CWF-52P-8, CWF-26P-11, and ACWF-26N2-11 at the sodalite-glass interface denoted by the vertical dotted lines. The linescan regions are denoted by the red boxes in the SEM micrographs. 


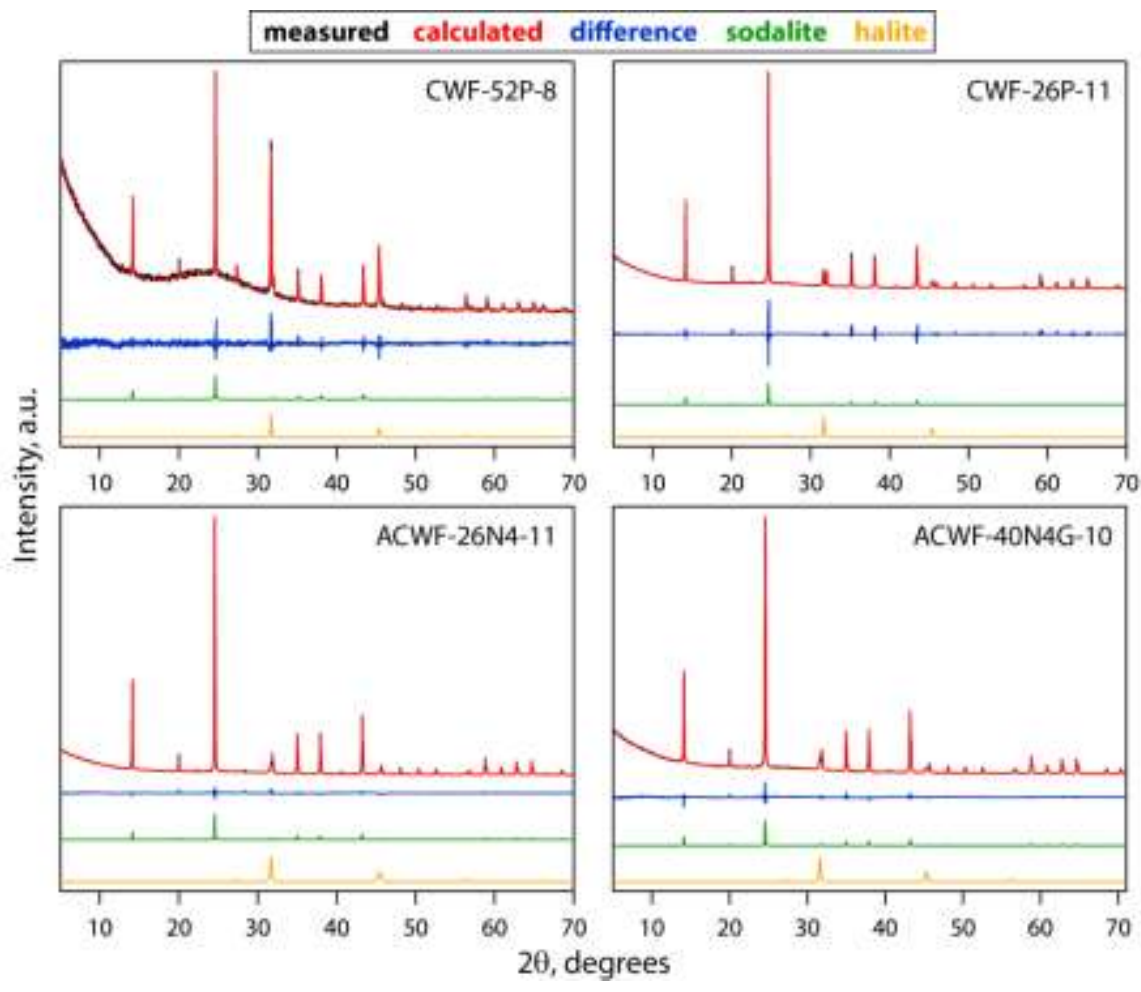

Figure 11. PXRD spectra for CWF-52P-8, CWF-26P-11, ACWF-26N4-11, and ACWF-40N4G-10. They key at the top of the figure is valid for all of the individual figures. 


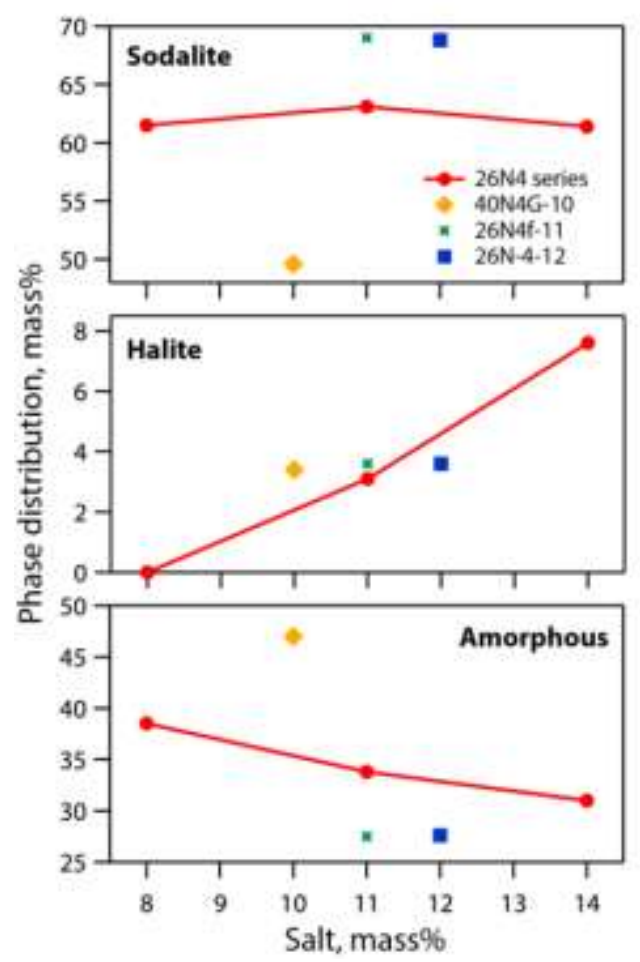

Figure 12. Phase distribution (PXRD) trends for the NBS-4 sample series (see Table 7). The red circles include samples ACWF-26N4-8 (8 mass\%), ACWF-26N4-11 (11 mass\%), and ACWF-26N4-14 (14 mass\%). 

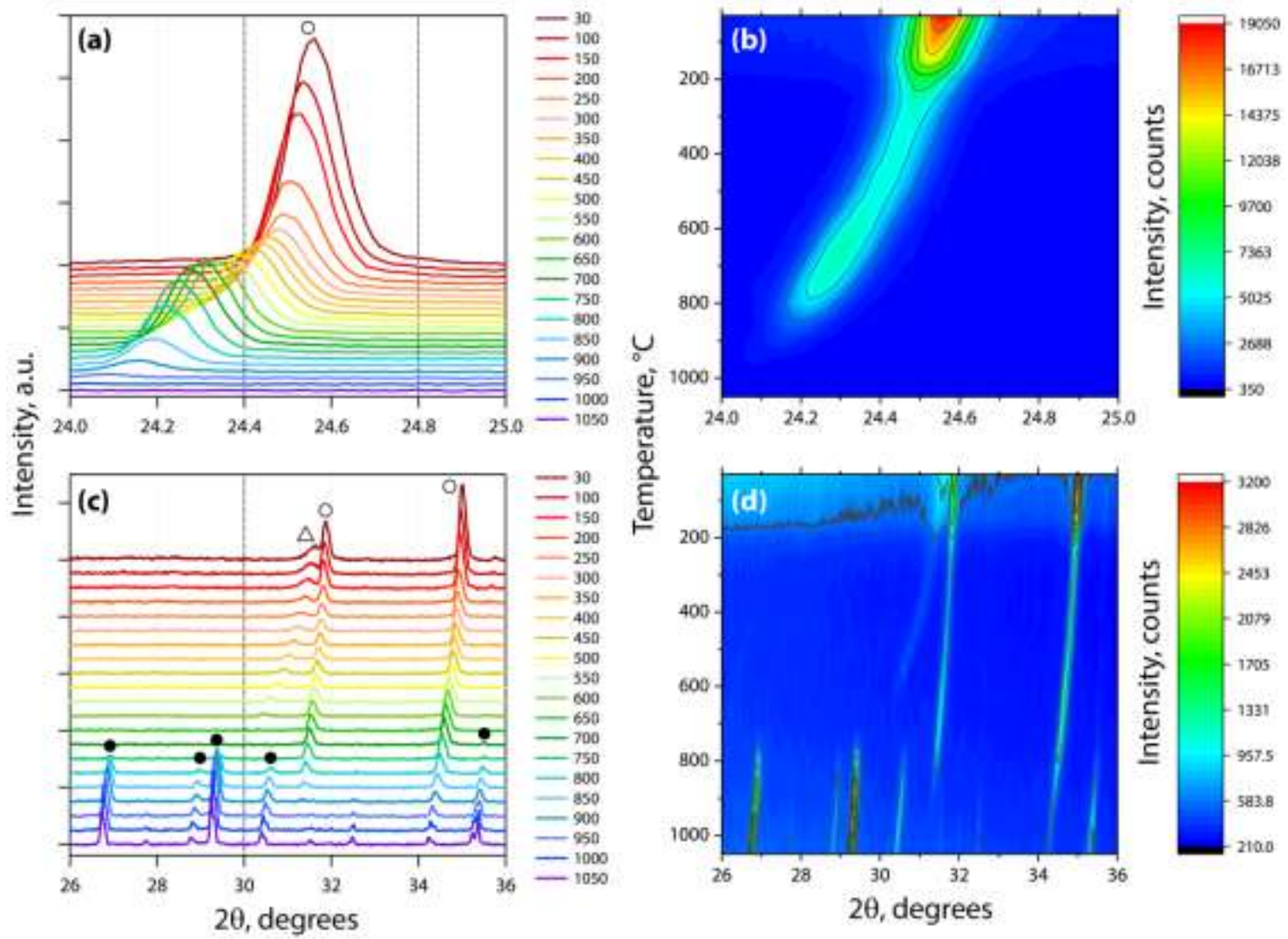

Figure 13. HS-XRD waterfall plots of various $2 \theta$ regions on the spectra from ACWF-26N4-11 showing (a,b) the primary sodalite peak shifting and decreasing in intensity with temperature $\left({ }^{\circ} \mathrm{C}\right)$ and $(\mathrm{c}, \mathrm{d})$ the nepheline peaks growing in as the secondary sodalite peaks decrease in intensity with increasing temperature. In both plots, sodalite, halite, and nepheline peaks are represented by the symbols $\circ, \Delta$, and $\bullet$, respectively. Plots in (a) and (c) are offset stacked plots whereas (b) and (d) are 2-dimensional contour plots.

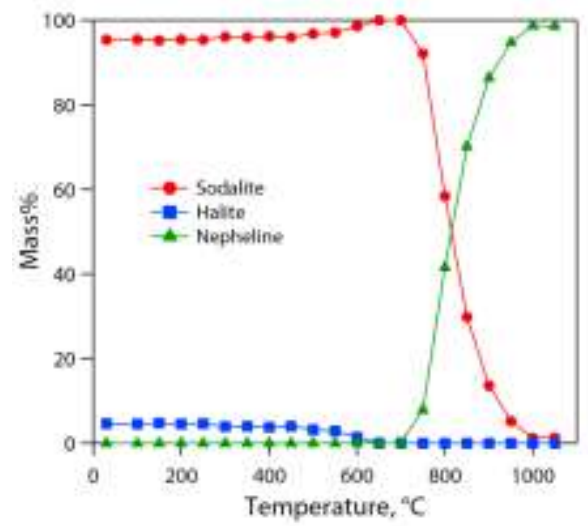

Figure 14. Distribution of sodalite, halite, and nepheline as a function of temperature for the HS-XRD experiment on ACWF-26N4-11. 

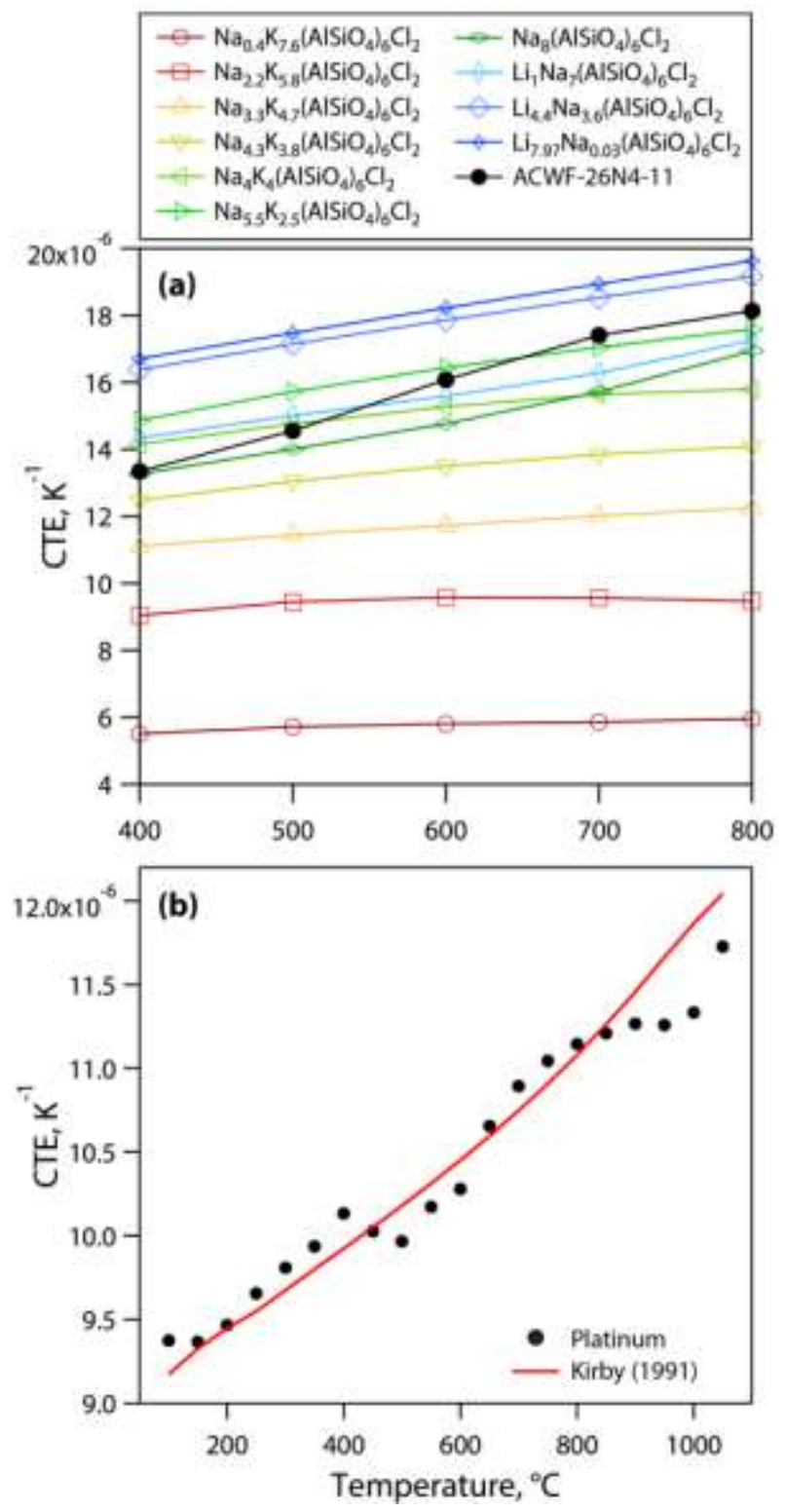

Figure 15. (a) CTE for ACWF-26N4-11 (•) as well as literature values calculated for specific temperatures based on polynomial fits through the data from Henderson and Taylor [36] for a variety of chlorosodalite compositions with different combinations of the alkali present in the system studied in the current work. (b) CTE for platinum heater strip as well as literature values from Kirby [46]. 


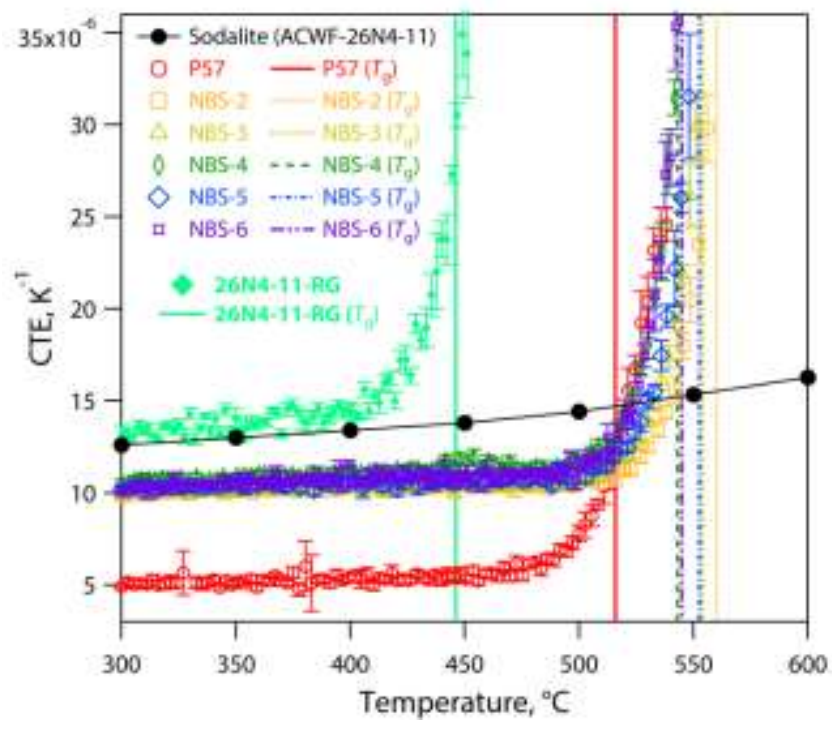

Figure 16. CTE comparison between sodalite from ACWF-26N4-11 and the glass binders from $300{ }^{\circ} \mathrm{C}$ to a temperature near $T_{\mathrm{g}}$ for each glass. The $\boldsymbol{T}_{\mathrm{g}}$ values for each glass are shown on the plot as vertical lines. 

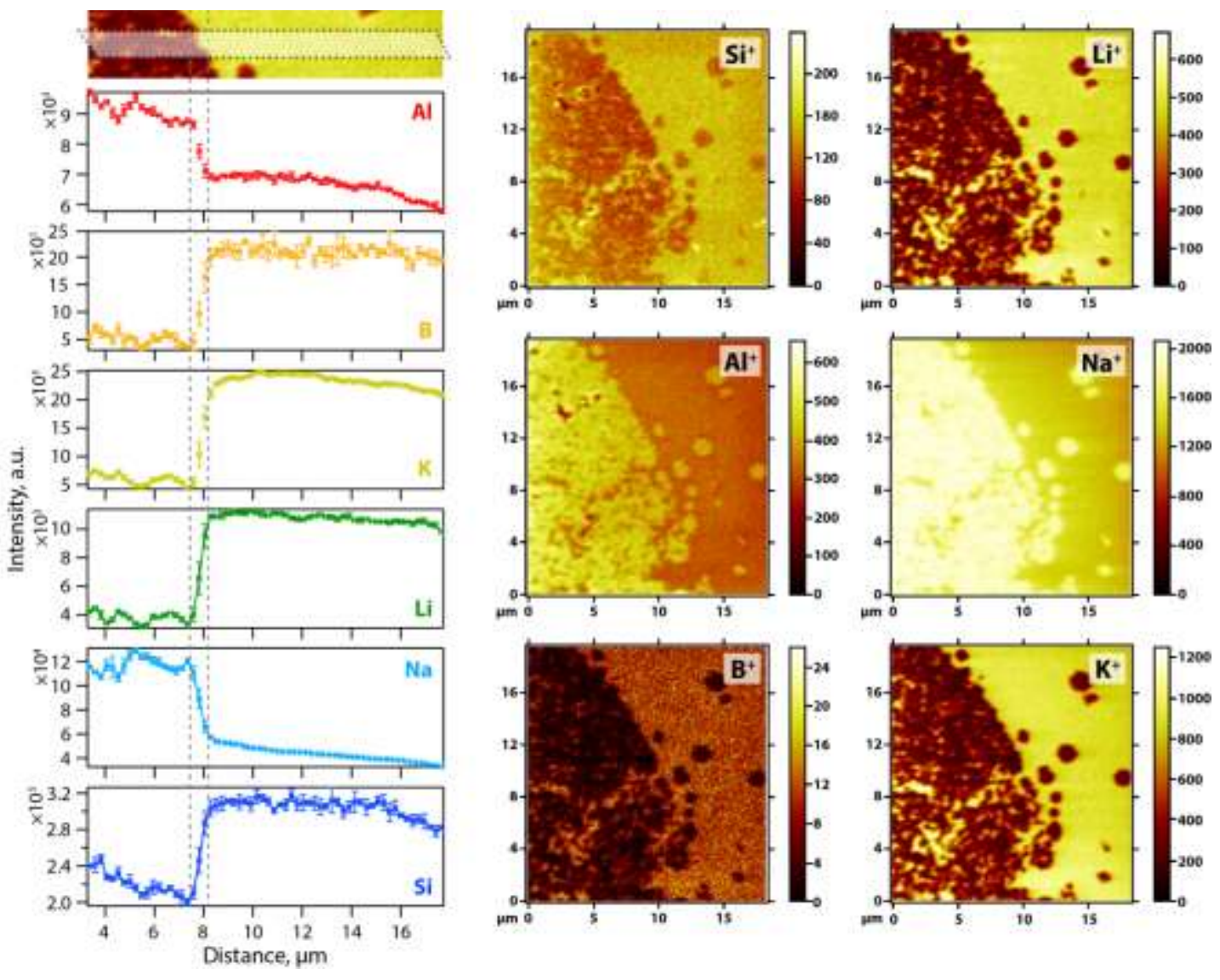

Figure 17. ToF-SIMS data for ACWF-26N3-11. (left) Linescan data showing elemental distributions across the field of view seen above in the image across the interface between the sodalite grains and the glass phase. (right) Data showing the distribution of $\mathrm{Si}^{+}, \mathrm{Al}^{+}, \mathrm{B}^{+}, \mathrm{Na}^{+}, \mathrm{Li}^{+}$, and $\mathrm{K}^{+}$across the sodalite-glass interface. 

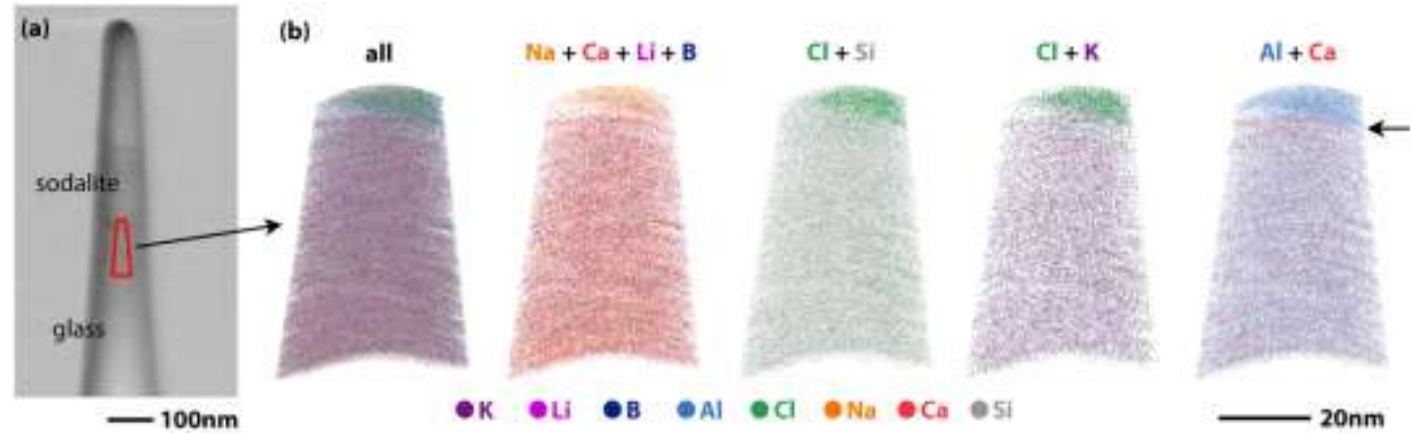

Figure 18. Atom probe tomography collage for ACWF-26N4-11 showing (a) the BSE-SEM micrograph of the sample tip removed with the FIB and (b) four elemental maps. The glass-sodalite interface is denoted by the arrow at the top right of the " $\mathrm{Cl}+\mathrm{K}$ " map. 


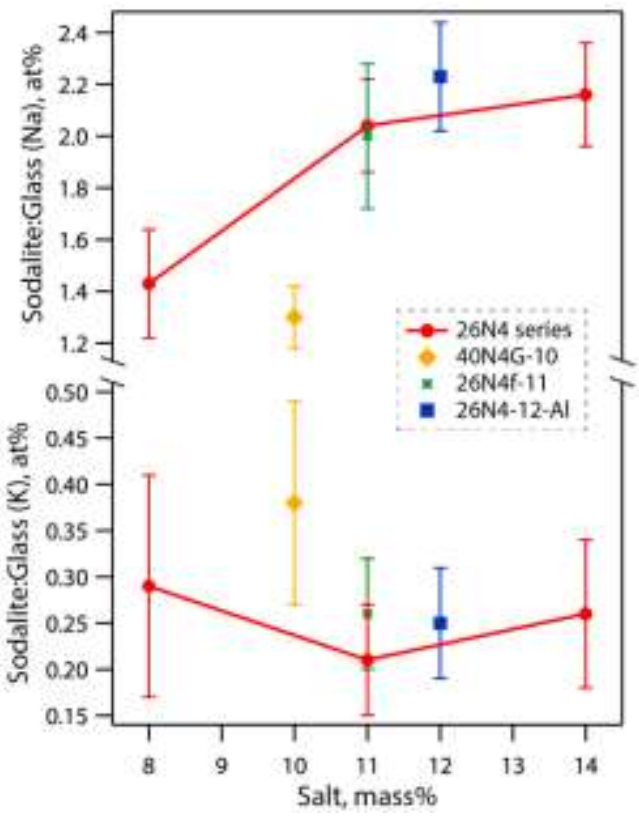

Figure 19. Sodalite:glass ratios (at \%) of $\mathrm{Na}$ (top) and $\mathrm{K}$ (bottom) in the series of samples made with NBS-4. The red circles include samples ACWF-26N4-8 (8 mass\%), ACWF-26N4-11 (11 mass\%), and ACWF-26N414 (14 mass\%). 


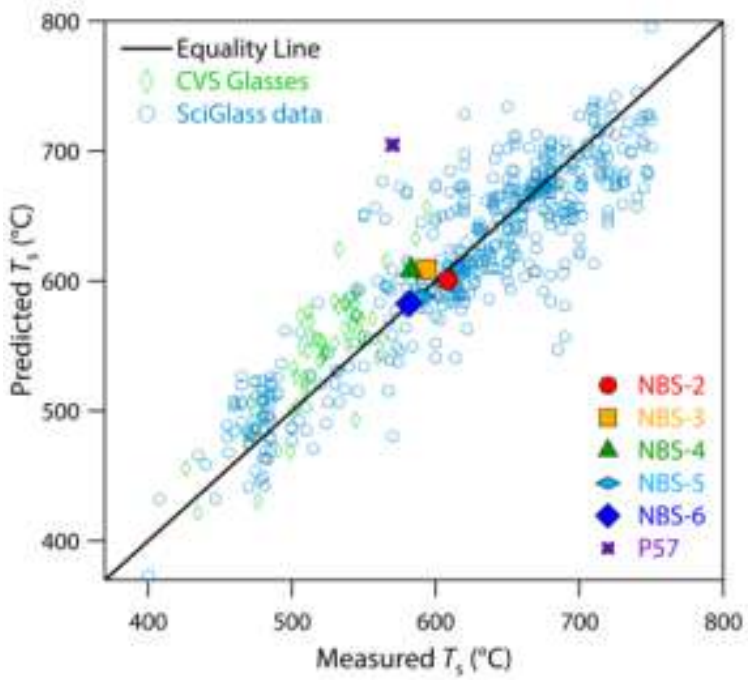

Figure 20. Predicted $T_{\mathrm{s}}$ values using model versus measured $T_{\mathrm{s}}$ values. Data points for all of the new NBS-\# glasses are plotted here as well as data for the P57 glass. 
Tables

Table 1. Old and new glass binder compositions, in mass\%, showing the P57 composition per specification [22], (*) the $\mathrm{P57}$ composition modified from the original with added 0.5 mass $\% \mathrm{Na}_{2} \mathrm{SO}_{4}$ as a fining agent, and NBS-1 [25] for comparison with the new glass binders (NBS-2 - NBS-6).

\begin{tabular}{|l|c|c|c|c|c|c|c|c|c|}
\hline Glass ID & $\mathbf{S i O}_{2}$ & $\mathbf{B}_{2} \mathbf{O}_{\mathbf{3}}$ & $\mathbf{A l}_{\mathbf{2}} \mathbf{O}_{\mathbf{3}}$ & $\mathbf{C a O}$ & $\mathbf{N a}_{\mathbf{2}} \mathbf{O}$ & $\mathbf{L i}_{\mathbf{2}} \mathbf{O}$ & $\mathbf{Z r O}_{\mathbf{2}}$ & $\mathbf{S U M}$ & $\boldsymbol{T}_{\mathbf{M}}$ \\
\hline P57 & 66.91 & 18.80 & 7.16 & - & 6.83 & 0.30 & - & 100.00 & 1550 \\
\hline P57* & 66.70 & 18.80 & 7.15 & - & 7.05 & 0.30 & - & 100.00 & 1550 \\
\hline NBS-1 & 60.00 & 10.00 & 5.00 & - & 15.00 & 5.00 & 5.00 & 100.00 & - \\
\hline NBS-2 & 59.87 & 9.98 & 4.99 & - & 20.17 & - & 4.99 & 100.00 & 1550 \\
\hline NBS-3 & 58.88 & 8.98 & 8.98 & - & 20.17 & - & 2.99 & 100.00 & 1550 \\
\hline NBS-4 & 58.87 & 8.98 & 5.99 & 3.99 & 20.17 & - & 2.00 & 100.00 & 1550 \\
\hline NBS-5 & 50.90 & 16.46 & 8.98 & - & 20.17 & - & 3.49 & 100.00 & 1450 \\
\hline NBS-6 & 49.02 & 18.80 & 8.65 & - & 20.17 & - & 3.36 & 100.00 & 1350 \\
\hline
\end{tabular}

Table 2. Measured composition of salt simulant (mass \%) where all components listed are fission products except $\mathrm{K}, \mathrm{Li}, \mathrm{Cl}$, and $\mathrm{Na}$ where $\mathrm{Na}$ is bonded to the fuel. * $\mathrm{K}$ contribution is from both $\mathrm{KCl}$ and $\mathrm{KI}$. Note that Ce was an impurity in one of the $\mathrm{LnCl}_{3}$ constituents.

\begin{tabular}{|l|c|}
\hline Element & Mass\% \\
\hline $\mathrm{Cl}$ & 58.72 \\
\hline $\mathrm{K}^{*}$ & 21.50 \\
\hline $\mathrm{Li}$ & 5.30 \\
\hline $\mathrm{Cs}$ & 4.00 \\
\hline $\mathrm{Na}$ & 3.80 \\
\hline $\mathrm{I}$ & 2.31 \\
\hline $\mathrm{Sr}$ & 1.69 \\
\hline $\mathrm{Nd}$ & 1.13 \\
\hline $\mathrm{La}$ & 0.86 \\
\hline $\mathrm{Y}$ & 0.69 \\
\hline $\mathrm{Ce}$ & 0.001 \\
\hline $\mathrm{SUM}$ & 100.00 \\
\hline $\mathrm{WL}:$ & 10.68 \\
\hline
\end{tabular}


Table 3. Sample preparation details. All samples were heated at $925^{\circ} \mathrm{C}$ for the time specified. For the "Crucible type" designation, "GC" = glassy carbon.

\begin{tabular}{|c|c|c|c|c|c|c|c|c|}
\hline Sample ID & Alt. ID & Binder & $\begin{array}{l}\text { SOZ } \\
\text { (mass, g) }\end{array}$ & $\begin{array}{l}\text { Glass } \\
\text { (mass, } \mathbf{g})\end{array}$ & $\begin{array}{l}\text { SOZ:GB } \\
(\operatorname{mass} \%)\end{array}$ & $\begin{array}{l}\text { Salt loading } \\
\text { (mass\%) }\end{array}$ & $\begin{array}{l}\text { Heat-treatment } \\
\text { time (hr) }\end{array}$ & $\begin{array}{l}\text { Crucible } \\
\text { type }\end{array}$ \\
\hline CWF-52P-8 & P1-8 & P57 & 23.7235 & 25.6321 & $48: 52$ & 8 & 16 & GC \\
\hline CWF-26P-11 & P6-11 & P57 & 36.9340 & 13.0200 & $74: 26$ & 11 & 5 & GC \\
\hline CWF-25P-8 & $\mathrm{P} 7-8$ & P57 & 36.7129 & 12.2299 & $75: 25$ & 8 & 24 & $\mathrm{GC}$ \\
\hline ACWF-26N2-11 & N2-11 & NBS-2 & 36.9751 & 13.0314 & $74: 26$ & 11 & 16 & GC \\
\hline ACWF-26N3-11 & N3-11 & NBS-3 & 36.9799 & 13.0272 & $74: 26$ & 11 & 16 & $\mathrm{GC}$ \\
\hline ACWF-26N4-11 & N4-11 & NBS-4 & 36.9879 & 13.0302 & $74: 26$ & 11 & 16 & GC \\
\hline ACWF-26N5-11 & N5-11 & NBS-5 & 36.9853 & 13.0223 & $74: 26$ & 11 & 16 & GC \\
\hline ACWF-26N6-11 & N6-11 & NBS-6 & 36.7095 & 12.8590 & $74: 26$ & 11 & 24 & GC \\
\hline ACWF-26N6-11-Al & N6-11-Al & NBS-6 & 37.0015 & 12.9073 & $74: 26$ & 11 & 24 & $\mathrm{Al}_{2} \mathrm{O}_{3}$ \\
\hline ACWF-26N4-8 & $\mathrm{N} 4-8$ & NBS-4 & 34.5893 & 12.1171 & $74: 26$ & 8 & 24 & GC \\
\hline ACWF-26N4f-11* & $\mathrm{N} 4 \mathrm{f}-11$ & NBS-4 & 36.9929 & 13.0122 & $74: 26$ & 11 & 24 & $\mathrm{GC}$ \\
\hline ACWF-26N4-12 & $\mathrm{N} 4-12$ & NBS-4 & 36.9694 & 13.0353 & $74: 26$ & 12 & 24 & $\mathrm{Al}_{2} \mathrm{O}_{3}$ \\
\hline ACWF-26N4-14 & N4-14 & NBS-4 & 36.9958 & 13.0846 & $74: 26$ & 14 & 24 & GC \\
\hline ACWF-40N4G-10 & N4G-10 & NBS-4 & 29.9985 & 19.9578 & $60: 40$ & 10 & 24 & $\mathrm{Al}_{2} \mathrm{O}_{3}$ \\
\hline
\end{tabular}

*A finer starting material was used for all of the reactants; for the zeolite 4A and glass binder, $<74-\mu \mathrm{m}(<200$ mesh $)$ powders were used, and for the salt, a finer-ground material (size was not determined) was used. 
Table 4. Compositions of NBS-4 and 26N4-11-RG (residual glass from ACWF-26N4-11) on a mass basis.

\begin{tabular}{|l|c|c|}
\hline Component & NBS-4 & 26N4-11-RG \\
\hline $\mathrm{Al}_{2} \mathrm{O}_{3}$ & 5.99 & 12.12 \\
\hline $\mathrm{B}_{2} \mathrm{O}_{3}$ & 8.98 & 6.24 \\
\hline $\mathrm{CaO}$ & 3.99 & 2.77 \\
\hline $\mathrm{Cs}{ }_{2} \mathrm{O}$ & - & 1.22 \\
\hline $\mathrm{K}_{2} \mathrm{O}$ & - & 5.81 \\
\hline $\mathrm{La}_{2} \mathrm{O}_{3}$ & - & 0.30 \\
\hline $\mathrm{Li}_{2} \mathrm{O}$ & - & 2.50 \\
\hline $\mathrm{Na}_{2} \mathrm{O}$ & 20.17 & 14.78 \\
\hline $\mathrm{Nd}_{2} \mathrm{O}_{3}$ & - & 0.39 \\
\hline $\mathrm{SiO}_{2}$ & 58.87 & 51.63 \\
\hline $\mathrm{SrO}_{\mathrm{Y} O}$ & - & 0.59 \\
\hline $\mathrm{Y}_{2} \mathrm{O}_{3}$ & - & 0.26 \\
\hline $\mathrm{ZrO}$ & 2.00 & 1.39 \\
\hline $\mathrm{SUM}_{2}$ & $\mathbf{1 0 0 . 0 0}$ & $\mathbf{1 0 0 . 0 0}$ \\
\hline
\end{tabular}


Table 5. Summary of optimization parameters for calculating the residual glass for ACWF-26N4-11-RG

\begin{tabular}{|c|c|c|c|c|c|}
\hline Parameter & Criterion & $p_{\mathrm{t}}$ & $p_{\mathrm{c}}$ & $\left(p_{t}-p_{c}\right)^{2}$ & $w_{\mathrm{f}}$ \\
\hline \multirow{3}{*}{$\begin{array}{l}\text { Phase amount from XRD } \\
(\operatorname{mass} \%)\end{array}$} & Halite & 3.1 & 1.6 & $2.31 \mathrm{E}-04$ & 250 \\
\hline & Sodalite & 63.1 & 62.0 & $1.12 \mathrm{E}-04$ & 500 \\
\hline & Glass & 33.8 & 36.4 & $6.65 \mathrm{E}-04$ & 100 \\
\hline \multirow{3}{*}{$\begin{array}{l}\text { Sodalite:glass } \\
\text { (ToF-SIMS) }\end{array}$} & $\mathrm{Li}^{+}$ & 0.084 & 0.34 & 0.07 & 2 \\
\hline & $\mathrm{Na}^{+}$ & 2.06 & 2.38 & 0.10 & 2 \\
\hline & $\mathrm{K}^{+}$ & 0.071 & 0.31 & 0.06 & 2 \\
\hline \multirow{2}{*}{$\begin{array}{l}\text { Sodalite:glass } \\
\text { (EDS) }\end{array}$} & $\mathrm{Na}$ & 2.04 & 2.38 & 0.12 & 0 \\
\hline & $\mathrm{K}$ & 0.21 & 0.31 & 0.01 & 0 \\
\hline \multirow{5}{*}{$\begin{array}{l}\text { Sodalite stoichiometry } \\
\text { (moles per unit) }\end{array}$} & $\mathrm{Na}+\mathrm{K}+\mathrm{Li}+\mathrm{Cs}$ & 8.0 & 7.3 & 0.43 & 1 \\
\hline & $\mathrm{Si}$ & 6.0 & 6.0 & 0.00 & 1 \\
\hline & $\mathrm{Al}$ & 6.0 & 6.1 & 0.02 & 1 \\
\hline & $\mathrm{Cl}+\mathrm{I}$ & 2.0 & 2.5 & 0.23 & 1 \\
\hline & $\mathrm{O}$ & 24.0 & 24.8 & 0.62 & 0.1 \\
\hline \multirow{3}{*}{$\begin{array}{l}\text { Anticipated partition to glass } \\
\text { (mass fraction) }\end{array}$} & $\mathrm{Cl}$ & $1.00 \mathrm{E}-06$ & $9.05 \mathrm{E}-03$ & $8.19 \mathrm{E}-05$ & 100 \\
\hline & Cs & 1.00 & 0.98 & $3.40 \mathrm{E}-04$ & 2 \\
\hline & I & $1.00 \mathrm{E}-06$ & $2.36 \mathrm{E}-04$ & $5.54 \mathrm{E}-08$ & 100 \\
\hline \multirow{2}{*}{$\begin{array}{l}\text { Halite } \\
\text { (molar ratio) }\end{array}$} & $\mathrm{Na}$ & 0.5 & 0.5 & 0 & 2.5 \\
\hline & $\mathrm{Cl}$ & 0.5 & 0.5 & 0 & 2.5 \\
\hline
\end{tabular}


Table 6. Glass binder characterizations including bulk pycnometry density $\left(\rho_{\mathrm{b}, \mathrm{p}}\right)$ and thermal properties. The top entry for P57 are data reported by O'Holleran [42] and the second entry for P57 (with the *) is a data point collected on the glass made with $\mathrm{Na}_{2} \mathrm{SO}_{4}$ fining agent added to the powdered frit. The $\boldsymbol{R}^{2}$ is the average correlation coefficient from different runs for that expansion vs temperature trendline with the temperature ranges in parentheses. The CTE values are presented for two temperature ranges $T<T_{\mathrm{g}}$ and $T_{\mathrm{g}}<T<T_{\mathrm{s}}$. Values are presented as averages with standard deviations in parenthesis (if available).

\begin{tabular}{|c|c|c|c|c|c|c|c|c|}
\hline \multirow{2}{*}{ Glass ID } & \multirow{2}{*}{$\frac{\rho_{\mathrm{b}, \mathrm{p}}}{\left(\times 10^{3} \mathrm{~kg} \mathrm{~m}^{-3}\right)}$} & \multicolumn{3}{|c|}{$R^{2}$ values for fits } & \multirow{2}{*}{$\begin{array}{c}T_{\mathrm{g}} \\
\left({ }^{\circ} \mathbf{C}\right)\end{array}$} & \multirow{2}{*}{$\begin{array}{c}\boldsymbol{T}_{\mathrm{s}} \\
\left({ }^{\circ} \mathbf{C}\right)\end{array}$} & \multicolumn{2}{|c|}{$\mathrm{CTE}\left(\times 10^{-6} \mathrm{~K}^{-1}\right)$} \\
\hline & & $T<T_{\mathrm{g}}$ & $T_{\mathrm{g}}<T<T_{\mathrm{s}}$ & $T>T_{\mathrm{s}}$ & & & $T<T_{\mathrm{g}}$ & $T_{\mathrm{g}}<T<T_{\mathrm{s}}$ \\
\hline P57 & - & - & - & - & 507 & 567 & - & - \\
\hline P57* & $\begin{array}{c}2.2690 \\
(0.0035)\end{array}$ & $\begin{array}{c}0.9999 \\
\left(343-477^{\circ} \mathrm{C}\right)\end{array}$ & $\begin{array}{c}0.9988 \\
\left(527-548^{\circ} \mathrm{C}\right)\end{array}$ & $\begin{array}{c}0.9798 \\
\left(583-599^{\circ} \mathrm{C}\right)\end{array}$ & 515.9 & 570.2 & 5.36 & 23.41 \\
\hline NBS-2 & $\begin{array}{c}2.5587 \\
(0.0027)\end{array}$ & $\begin{array}{c}1.0000 \\
\left(283-513^{\circ} \mathrm{C}\right)\end{array}$ & $\begin{array}{c}0.9979 \\
\left(572-584^{\circ} \mathrm{C}\right)\end{array}$ & $\begin{array}{c}0.9921 \\
\left(622-631^{\circ} \mathrm{C}\right)\end{array}$ & $\begin{array}{r}560.1 \\
(0.4) \\
\end{array}$ & $\begin{array}{r}608.4 \\
(1.1) \\
\end{array}$ & $\begin{array}{l}10.15 \\
(0.11)\end{array}$ & $\begin{array}{l}80.72 \\
(0.24)\end{array}$ \\
\hline NBS-3 & $\begin{array}{c}2.4851 \\
(0.0015)\end{array}$ & $\begin{array}{c}1.0000 \\
\left(280-516^{\circ} \mathrm{C}\right)\end{array}$ & $\begin{array}{c}0.9971 \\
\left(565-577^{\circ} \mathrm{C}\right)\end{array}$ & $\begin{array}{c}0.9875 \\
\left(605-617^{\circ} \mathrm{C}\right)\end{array}$ & $\begin{array}{r}553.9 \\
(0.1)\end{array}$ & $\begin{array}{r}593.8 \\
(5.5)\end{array}$ & $\begin{array}{l}10.24 \\
(0.09)\end{array}$ & $\begin{array}{l}75.20 \\
(2.55)\end{array}$ \\
\hline NBS-4 & $\begin{array}{c}2.5247 \\
(0.0017)\end{array}$ & $\begin{array}{c}1.0000 \\
\left(255-492^{\circ} \mathrm{C}\right)\end{array}$ & $\begin{array}{c}0.9969 \\
\left(555-565^{\circ} \mathrm{C}\right) \\
\end{array}$ & $\begin{array}{c}0.9848 \\
\left(590-605^{\circ} \mathrm{C}\right)\end{array}$ & $\begin{array}{r}543.1 \\
(0.3) \\
\end{array}$ & $\begin{array}{r}582.8 \\
(4.0) \\
\end{array}$ & $\begin{array}{l}10.99 \\
(0.32)\end{array}$ & $\begin{array}{l}72.43 \\
(3.79) \\
\end{array}$ \\
\hline NBS-5 & $\begin{array}{c}2.4889 \\
(0.0027) \\
\end{array}$ & $\begin{array}{c}0.9999 \\
\left(237-499^{\circ} \mathrm{C}\right) \\
\end{array}$ & $\begin{array}{c}0.9979 \\
\left(563-572^{\circ} \mathrm{C}\right) \\
\end{array}$ & $\begin{array}{c}0.9878 \\
\left(602-611^{\circ} \mathrm{C}\right) \\
\end{array}$ & $\begin{array}{r}552.5 \\
(0.7) \\
\end{array}$ & $\begin{array}{r}590.5 \\
(1.2) \\
\end{array}$ & $\begin{array}{l}10.52 \\
(0.04) \\
\end{array}$ & $\begin{array}{l}97.97 \\
(2.11) \\
\end{array}$ \\
\hline NBS-6 & $\begin{array}{c}2.5290 \\
(0.0004)\end{array}$ & $\begin{array}{c}0.9998 \\
\left(259-510^{\circ} \mathrm{C}\right)\end{array}$ & $\begin{array}{c}0.9979 \\
\left(553-566^{\circ} \mathrm{C}\right)\end{array}$ & $\begin{array}{c}0.9864 \\
\left(589-600^{\circ} \mathrm{C}\right)\end{array}$ & $\begin{array}{r}544.9 \\
(1.3)\end{array}$ & $\begin{array}{r}581.5 \\
(2.2)\end{array}$ & $\begin{array}{l}10.64 \\
(0.04)\end{array}$ & $\begin{array}{l}86.25 \\
(1.57)\end{array}$ \\
\hline 26N4-11-RG & $\begin{array}{c}2.5638 \\
(0.0019)\end{array}$ & $\begin{array}{c}0.9997 \\
\left(250-405^{\circ} \mathrm{C}\right)\end{array}$ & $\begin{array}{c}0.9972 \\
\left(457-470^{\circ} \mathrm{C}\right)\end{array}$ & $\begin{array}{c}0.9782 \\
\left(490-498^{\circ} \mathrm{C}\right)\end{array}$ & $\begin{array}{r}446.2 \\
(0.7)\end{array}$ & $\begin{array}{r}482.2 \\
(2.1)\end{array}$ & $\begin{array}{l}13.43 \\
(0.11)\end{array}$ & $\begin{array}{l}56.26 \\
(0.09)\end{array}$ \\
\hline
\end{tabular}


Table 7. CWF characterization including X-ray diffraction, bulk pycnometric density $\left(\rho_{\mathrm{b}, \mathrm{p}}\right)$, bulk geometric density $\left(\rho_{\mathrm{b}, \mathrm{g}}\right)$, Archimedes density $\left(\rho_{\mathrm{a}}\right)$, theoretical density $\left(\rho_{t}\right)$, open porosity (vol\%) determined by Archimedes method $\left(\phi_{\mathrm{a}}\right)$, open porosity (area \%) determined by image analysis of SEM micrographs $\left(\phi_{\mathrm{SEM}}\right)$, the density ration (DR, or \% of $\left.\rho_{t}\right)$, and specific surface area (SSA) with standard deviations in parentheses in cases where multiple values were averaged. "Amor." denotes the amorphous phase.

\begin{tabular}{|c|c|c|c|c|c|c|c|c|c|c|c|c|c|c|c|}
\hline \multirow{2}{*}{$\begin{array}{l}\text { Sample } \\
\text { ID }\end{array}$} & \multirow{2}{*}{$\begin{array}{l}\text { Alt. } \\
\text { ID }\end{array}$} & \multirow{2}{*}{$\begin{array}{l}\text { Glass } \\
\text { Binder }\end{array}$} & Glass & Salt & \multicolumn{3}{|c|}{ Phase distribution (mass\%) } & $\rho_{\mathrm{b}, \mathbf{p}}$ & $\rho_{\mathrm{b}, \mathrm{g}}$ & $\rho_{\mathrm{a}}$ & $\rho_{\mathrm{t}}$ & \multirow{2}{*}{$\frac{\phi_{a}}{(\mathrm{Vol} \%)}$} & \multirow{2}{*}{$\frac{\phi_{\mathrm{SEM}}}{(\text { Area } \%)}$} & \multirow{2}{*}{$\frac{\text { DR }}{\% \text { of } \rho_{\mathrm{t}}}$} & \multirow{2}{*}{$\frac{\text { SSA }}{\mathrm{m}^{2} \mathrm{~g}^{-1}}$} \\
\hline & & & \multicolumn{2}{|c|}{ Mass \% } & Sodalite & $\mathrm{NaCl}$ & Amor. & \multicolumn{4}{|c|}{$\left(\times 10^{3} \mathrm{~kg} \mathrm{~m}^{-3}\right)$} & & & & \\
\hline CWF-52P-8 & P1-8 & P57 & 52 & 8 & 8.5 & 5.5 & 86.0 & \begin{tabular}{|r|}
2.149 \\
$(0.000)$ \\
\end{tabular} & 2.113 & $\begin{array}{c}2.126 \\
(0.017) \\
\end{array}$ & 2.264 & $\begin{array}{c}0.074 \\
(0.048) \\
\end{array}$ & $\begin{array}{c}3.53 \\
(1.19)\end{array}$ & 93.3 & $\begin{array}{c}0.0065 \\
(0.0000) \\
\end{array}$ \\
\hline CWF-26P-11 & P6-11 & P57 & 26 & 11 & 38.9 & 4.2 & 56.9 & \begin{tabular}{|r|}
2.298 \\
$(0.002)$ \\
\end{tabular} & 1.373 & $\begin{array}{c}1.544 \\
(0.089) \\
\end{array}$ & 2.271 & $\begin{array}{l}32.62 \\
(3.60) \\
\end{array}$ & $\begin{array}{l}43.19 \\
(6.71) \\
\end{array}$ & 60.5 & $\begin{array}{c}0.0886 \\
(0.0004) \\
\end{array}$ \\
\hline CWF-25P-8 & P7-8 & P57 & 25 & 8 & 42.3 & 1.9 & 55.8 & \begin{tabular}{|r|}
2.229 \\
$(0.001)$ \\
\end{tabular} & 1.793 & $\begin{array}{c}1.884 \\
(0.038) \\
\end{array}$ & 2.274 & $\begin{array}{l}14.23 \\
(2.04)\end{array}$ & $\begin{array}{l}15.48 \\
(6.35)\end{array}$ & 78.9 & $\begin{array}{c}0.0298 \\
(0.0004) \\
\end{array}$ \\
\hline ACWF-26N2-11 & $\mathrm{N} 2-11$ & NBS-2 & 26 & 11 & 57.5 & 2.9 & 39.6 & \begin{tabular}{|r|}
2.325 \\
$(0.001)$ \\
\end{tabular} & 1.244 & $\begin{array}{c}1.351 \\
(0.096) \\
\end{array}$ & 2.390 & $\begin{array}{l}41.98 \\
(3.78)\end{array}$ & $\begin{array}{l}43.42 \\
(3.21) \\
\end{array}$ & 52.1 & $\begin{array}{c}0.0745 \\
(0.0003) \\
\end{array}$ \\
\hline ACWF-26N3-11 & N3-11 & NBS-3 & 26 & 11 & 62.5 & 2.9 & 34.6 & \begin{tabular}{|r|}
2.331 \\
$(0.002)$ \\
\end{tabular} & 1.221 & $\begin{array}{c}1.297 \\
(0.017)\end{array}$ & 2.351 & $\begin{array}{l}44.14 \\
(0.37)\end{array}$ & $\begin{array}{l}44.09 \\
(5.14)\end{array}$ & 51.9 & $\begin{array}{c}0.1729 \\
(0.0008)\end{array}$ \\
\hline ACWF-26N4-11 & N4-11 & NBS-4 & 26 & 11 & 63.1 & 3.1 & 33.8 & \begin{tabular}{|r|}
2.340 \\
$(0.001)$ \\
\end{tabular} & 1.221 & $\begin{array}{c}1.283 \\
(0.014) \\
\end{array}$ & 2.362 & $\begin{array}{l}44.92 \\
(0.37) \\
\end{array}$ & $\begin{array}{l}53.14 \\
(3.82) \\
\end{array}$ & 51.7 & $\begin{array}{c}0.1032 \\
(0.0005) \\
\end{array}$ \\
\hline ACWF-26N5-11 & N5-11 & NBS-5 & 26 & 11 & 62.6 & 2.6 & 34.8 & \begin{tabular}{|r|}
2.326 \\
$(0.001)$ \\
\end{tabular} & 1.419 & $\begin{array}{c}1.443 \\
(0.000)\end{array}$ & 2.353 & $\begin{array}{l}37.57 \\
(0.32)\end{array}$ & $\begin{array}{l}35.31 \\
(6.44)\end{array}$ & 60.3 & $\begin{array}{c}0.1378 \\
(0.0005) \\
\end{array}$ \\
\hline ACWF-26N6-11 & N6-11 & NBS-6 & 26 & 11 & 69.4 & 3.0 & 27.6 & \begin{tabular}{|r|}
2.303 \\
$(0.001)$ \\
\end{tabular} & 1.331 & $\begin{array}{c}1.356 \\
(0.050) \\
\end{array}$ & 2.349 & $\begin{array}{l}40.61 \\
(2.27) \\
\end{array}$ & $\begin{array}{l}39.30 \\
(2.71) \\
\end{array}$ & 56.7 & $\begin{array}{c}0.0470 \\
(0.0002) \\
\end{array}$ \\
\hline ACWF-26N6-11-Al & $\begin{array}{l}\mathrm{N} 6- \\
11-\mathrm{Al}\end{array}$ & NBS-6 & 26 & 11 & 68.0 & 2.4 & 29.6 & \begin{tabular}{|r|}
2.300 \\
$(0.001)$ \\
\end{tabular} & 1.410 & $\begin{array}{c}1.438 \\
(0.003) \\
\end{array}$ & 2.354 & $\begin{array}{l}37.28 \\
(0.02) \\
\end{array}$ & $\begin{array}{l}37.94 \\
(7.18) \\
\end{array}$ & 59.9 & $\begin{array}{c}0.0349 \\
(0.0003) \\
\end{array}$ \\
\hline ACWF-26N4-8 & N4-8 & NBS-4 & 26 & 8 & 61.5 & 0.0 & 38.5 & \begin{tabular}{|r|}
2.364 \\
$(0.002)$ \\
\end{tabular} & 1.286 & $\begin{array}{c}1.304 \\
(0.042)\end{array}$ & 2.377 & $\begin{array}{l}44.10 \\
(1.88)\end{array}$ & $\begin{array}{l}39.32 \\
(4.48)\end{array}$ & 54.1 & $\begin{array}{c}0.0545 \\
(0.0003) \\
\end{array}$ \\
\hline ACWF-26N4f-11 & $\begin{array}{l}\text { N4f- } \\
11 \\
\end{array}$ & NBS-4 & 26 & 11 & 68.9 & 3.6 & 27.5 & $\begin{array}{r}2.335 \\
(0.001) \\
\end{array}$ & 1.435 & $\begin{array}{c}1.447 \\
(0.000)\end{array}$ & 2.346 & $\begin{array}{c}38.06 \\
(0.52)\end{array}$ & $\begin{array}{l}39.81 \\
(0.62)\end{array}$ & 61.2 & $\begin{array}{c}0.1358 \\
(0.0007)\end{array}$ \\
\hline ACWF-26N4-12 & N4-12 & NBS-4 & 26 & 12 & 68.8 & 3.6 & 27.6 & \begin{tabular}{|r|}
2.324 \\
$(0.002)$ \\
\end{tabular} & 1.288 & $\begin{array}{c}1.366 \\
(0.050) \\
\end{array}$ & 2.347 & $\begin{array}{l}42.35 \\
(3.42) \\
\end{array}$ & $\begin{array}{l}33.11 \\
(7.77) \\
\end{array}$ & 54.9 & $\begin{array}{c}0.1028 \\
(0.0005) \\
\end{array}$ \\
\hline ACWF-26N4-14 & N4-14 & NBS-4 & 26 & 14 & 61.4 & 7.6 & 31.0 & \begin{tabular}{|r|}
2.325 \\
$(0.001)$ \\
\end{tabular} & 1.290 & $\begin{array}{c}1.397 \\
(0.040)\end{array}$ & 2.350 & $\begin{array}{l}39.65 \\
(1.48)\end{array}$ & $\begin{array}{l}26.03 \\
(3.20)\end{array}$ & 54.9 & $\begin{array}{c}0.0770 \\
(0.0006)\end{array}$ \\
\hline ACWF-40N4G-10 & N4G & NBS-4 & 40 & 10 & 49.6 & 3.4 & 47.0 & $\begin{array}{r}2.153 \\
(0.001) \\
\end{array}$ & 1.884 & $\begin{array}{c}1.902 \\
(0.003)\end{array}$ & 2.393 & $\begin{array}{c}7.97 \\
(0.47) \\
\end{array}$ & $\begin{array}{c}5.06 \\
(0.03) \\
\end{array}$ & 78.7 & $\begin{array}{c}0.0064 \\
(0.0000) \\
\end{array}$ \\
\hline
\end{tabular}


Table 8. Summary of alkali distributions between the glass and sodalite phases using EDS (at\%, excluding oxygen) and ToF-SIMS (in counts) where the data is presented with averages and standard deviation in parenthesis. All EDS data were collected from dot map locations (10 locations for each phase at $5 \mathrm{k} \times$ regions). All ToF-SIMS data were collected from mapped regions using areas (3 locations for N3-11 and 10 each for N4-11).

\begin{tabular}{|c|c|c|c|c|c|c|c|c|c|c|}
\hline \multirow{2}{*}{ Sample } & \multirow{2}{*}{ Method } & \multicolumn{3}{|c|}{ Sodalite } & \multicolumn{3}{|c|}{ Glass } & \multicolumn{3}{|c|}{ Sodalite:Glass } \\
\hline & & $\mathrm{Li}$ & $\mathrm{Na}$ & $\mathrm{K}$ & $\mathrm{Li}$ & $\mathrm{Na}$ & $\mathrm{K}$ & $\mathrm{Li}$ & $\mathrm{Na}$ & $\mathrm{K}$ \\
\hline CWF-52P-8 & EDS & - & $\begin{array}{c}26.54 \\
(1.26) \\
\end{array}$ & $\begin{array}{c}0.38 \\
(0.14) \\
\end{array}$ & - & $\begin{array}{c}12.45 \\
(0.30)\end{array}$ & $\begin{array}{c}5.06 \\
(0.39) \\
\end{array}$ & - & $\begin{array}{c}2.13 \\
(0.12) \\
\end{array}$ & $\begin{array}{c}0.08 \\
(0.03) \\
\end{array}$ \\
\hline CWF-26P-11 & EDS & - & $\begin{array}{c}23.57 \\
(1.43) \\
\end{array}$ & $\begin{array}{c}2.06 \\
(0.69) \\
\end{array}$ & - & $\begin{array}{l}11.50 \\
(0.16) \\
\end{array}$ & $\begin{array}{c}7.48 \\
(0.08) \\
\end{array}$ & - & $\begin{array}{c}2.05 \\
(0.12) \\
\end{array}$ & $\begin{array}{c}0.28 \\
(0.09) \\
\end{array}$ \\
\hline CWF-25P-8 & EDS & - & $\begin{array}{c}27.58 \\
(0.72) \\
\end{array}$ & $\begin{array}{c}0.48 \\
(0.19) \\
\end{array}$ & - & $\begin{array}{l}13.82 \\
(0.12) \\
\end{array}$ & $\begin{array}{c}6.13 \\
(0.10) \\
\end{array}$ & - & $\begin{array}{c}2.00 \\
(0.06) \\
\end{array}$ & $\begin{array}{c}0.08 \\
(0.03) \\
\end{array}$ \\
\hline ACWF-26N2-11 & EDS & - & $\begin{array}{c}25.94 \\
(1.56) \\
\end{array}$ & $\begin{array}{c}1.90 \\
(0.46) \\
\end{array}$ & - & $\begin{array}{c}15.04 \\
(0.16) \\
\end{array}$ & $\begin{array}{c}8.68 \\
(0.08) \\
\end{array}$ & - & $\begin{array}{c}1.73 \\
(0.12) \\
\end{array}$ & $\begin{array}{c}0.22 \\
(0.05) \\
\end{array}$ \\
\hline ACWF-26N3-11 & EDS & - & $\begin{array}{c}25.81 \\
(0.99)\end{array}$ & $\begin{array}{c}2.16 \\
(0.44) \\
\end{array}$ & - & $\begin{array}{l}13.77 \\
(0.35)\end{array}$ & $\begin{array}{c}10.18 \\
(0.76) \\
\end{array}$ & - & $\begin{array}{c}1.88 \\
(0.09) \\
\end{array}$ & $\begin{array}{c}0.21 \\
(0.05)\end{array}$ \\
\hline ACWF-26N4-11 & EDS & - & $\begin{array}{l}28.65 \\
(2.17) \\
\end{array}$ & $\begin{array}{c}2.08 \\
(0.52) \\
\end{array}$ & - & $\begin{array}{l}14.10 \\
(0.37) \\
\end{array}$ & $\begin{array}{c}9.95 \\
(1.38) \\
\end{array}$ & - & $\begin{array}{c}2.04 \\
(0.18) \\
\end{array}$ & $\begin{array}{c}0.21 \\
(0.06) \\
\end{array}$ \\
\hline ACWF-26N5-11 & EDS & - & $\begin{array}{c}27.83 \\
(0.88) \\
\end{array}$ & $\begin{array}{c}1.53 \\
(0.39) \\
\end{array}$ & - & $\begin{array}{c}14.01 \\
(0.90) \\
\end{array}$ & $\begin{array}{l}11.14 \\
(1.62) \\
\end{array}$ & - & $\begin{array}{c}1.99 \\
(0.13) \\
\end{array}$ & $\begin{array}{c}0.14 \\
(0.04) \\
\end{array}$ \\
\hline ACWF-26N6-11 & EDS & - & $\begin{array}{l}32.09 \\
(3.63) \\
\end{array}$ & $\begin{array}{c}0.89 \\
(0.33) \\
\end{array}$ & - & $\begin{array}{l}15.94 \\
(0.92) \\
\end{array}$ & $\begin{array}{l}10.03 \\
(0.50) \\
\end{array}$ & - & $\begin{array}{c}2.02 \\
(0.23) \\
\end{array}$ & $\begin{array}{c}0.09 \\
(0.03) \\
\end{array}$ \\
\hline ACWF-26N6-11-Al & EDS & - & $\begin{array}{l}19.65 \\
(1.09)\end{array}$ & $\begin{array}{c}2.58 \\
(0.68) \\
\end{array}$ & - & $\begin{array}{l}13.10 \\
(0.38)\end{array}$ & $\begin{array}{c}10.40 \\
(0.15) \\
\end{array}$ & - & $\begin{array}{c}1.50 \\
(0.10) \\
\end{array}$ & $\begin{array}{c}0.25 \\
(0.07) \\
\end{array}$ \\
\hline ACWF-26N4-8 & EDS & - & $\begin{array}{c}28.95 \\
(2.30) \\
\end{array}$ & $\begin{array}{c}1.84 \\
(0.86) \\
\end{array}$ & - & $\begin{array}{c}20.50 \\
(2.03) \\
\end{array}$ & $\begin{array}{c}6.30 \\
(0.66) \\
\end{array}$ & - & $\begin{array}{c}1.43 \\
(0.21) \\
\end{array}$ & $\begin{array}{c}0.29 \\
(0.12) \\
\end{array}$ \\
\hline ACWF-26N4f-11 & EDS & - & $\begin{array}{l}27.68 \\
(2.82)\end{array}$ & $\begin{array}{c}2.68 \\
(0.75) \\
\end{array}$ & - & $\begin{array}{l}13.92 \\
(1.23)\end{array}$ & $\begin{array}{l}10.24 \\
(0.61)\end{array}$ & - & $\begin{array}{c}2.00 \\
(0.28)\end{array}$ & $\begin{array}{c}0.26 \\
(0.06)\end{array}$ \\
\hline ACWF-26N4-12 & EDS & - & $\begin{array}{c}27.71 \\
(1.42) \\
\end{array}$ & $\begin{array}{c}2.66 \\
(0.73) \\
\end{array}$ & - & $\begin{array}{l}12.48 \\
(0.93) \\
\end{array}$ & $\begin{array}{l}10.42 \\
(0.48) \\
\end{array}$ & - & $\begin{array}{c}2.23 \\
(0.21) \\
\end{array}$ & $\begin{array}{c}0.25 \\
(0.06) \\
\end{array}$ \\
\hline ACWF-26N4-14 & EDS & - & $\begin{array}{c}25.02 \\
(2.14)\end{array}$ & $\begin{array}{c}2.73 \\
(0.77) \\
\end{array}$ & - & $\begin{array}{c}11.58 \\
(0.46)\end{array}$ & $\begin{array}{l}10.79 \\
(0.41)\end{array}$ & - & $\begin{array}{c}2.16 \\
(0.20)\end{array}$ & $\begin{array}{c}0.26 \\
(0.08)\end{array}$ \\
\hline ACWF-40N4G-10 & EDS & - & $\begin{array}{c}24.60 \\
(2.28) \\
\end{array}$ & $\begin{array}{c}2.33 \\
(0.66) \\
\end{array}$ & - & $\begin{array}{c}18.96 \\
(0.54) \\
\end{array}$ & $\begin{array}{c}6.19 \\
(0.44) \\
\end{array}$ & - & $\begin{array}{c}1.30 \\
(0.12) \\
\end{array}$ & $\begin{array}{c}0.38 \\
(0.11) \\
\end{array}$ \\
\hline ACWF-26N3-11 & SIMS & $\begin{array}{c}1375 \\
(53) \\
\end{array}$ & $\begin{array}{l}17813 \\
(1254) \\
\end{array}$ & $\begin{array}{l}1571 \\
(45) \\
\end{array}$ & $\begin{array}{c}3552 \\
151 \\
\end{array}$ & $\begin{array}{r}11115 \\
(1436) \\
\end{array}$ & $\begin{array}{l}6935 \\
(411) \\
\end{array}$ & $\begin{array}{c}0.39 \\
(0.02) \\
\end{array}$ & $\begin{array}{c}1.61 \\
(0.15) \\
\end{array}$ & $\begin{array}{c}0.23 \\
(0.01) \\
\end{array}$ \\
\hline ACWF-26N4-11 & SIMS & $\begin{array}{c}595 \\
(208) \\
\end{array}$ & $\begin{array}{l}10131 \\
(1304)\end{array}$ & $\begin{array}{c}957 \\
(354) \\
\end{array}$ & $\begin{array}{l}7108 \\
(463) \\
\end{array}$ & $\begin{array}{l}4923 \\
(546)\end{array}$ & $\begin{array}{l}13445 \\
(1082)\end{array}$ & $\begin{array}{c}0.084 \\
(0.028)\end{array}$ & $\begin{array}{r}2.06 \\
(0.15) \\
\end{array}$ & $\begin{array}{c}0.071 \\
(0.025)\end{array}$ \\
\hline
\end{tabular}


Table 9. List of model components and coefficients over the compositional validity range (in mass fraction). Others is the sum of all components not specifically listed as model terms (i.e., those not anticipated to have a significant impact on $\left.T_{\mathrm{s}}\right)$. For this data, $R^{2}=0.8215, R_{\mathrm{A}}^{2}=0.8171\left(\right.$ adjusted $\left.R^{2}\right), R_{\mathrm{p}}^{2}=0.8119\left(R^{2}\right.$ press $), R_{\mathrm{V}}^{2}=$ 0.8309 (validation $R^{2}$ ), and root mean square error $=34.523^{\circ} \mathrm{C}$ under 585 observations.

\begin{tabular}{|l|c|c|r|}
\hline Component & Min & Max & $s_{\text {i values }}$ \\
\hline $\mathrm{Al}_{2} \mathrm{O}_{3}$ & 0.000 & 0.348 & 832 \\
\hline $\mathrm{B}_{2} \mathrm{O}_{3}$ & 0.000 & 0.467 & 559 \\
\hline $\mathrm{BaO}$ & 0.000 & 0.400 & 675 \\
\hline $\mathrm{CaO}$ & 0.000 & 0.305 & 745 \\
\hline $\mathrm{F}$ & 0.000 & 0.090 & -671 \\
\hline $\mathrm{K}_{2} \mathrm{O}$ & 0.000 & 0.284 & 286 \\
\hline $\mathrm{Li}_{2} \mathrm{O}$ & 0.000 & 0.191 & -1428 \\
\hline $\mathrm{MgO}$ & 0.000 & 0.230 & 572 \\
\hline $\mathrm{Na}_{2} \mathrm{O}$ & 0.000 & 0.302 & -71 \\
\hline $\mathrm{SiO}_{2}$ & 0.300 & 0.855 & 818 \\
\hline $\mathrm{SrO}^{2}$ & 0.000 & 0.151 & 749 \\
\hline $\mathrm{ZnO}$ & 0.000 & 0.233 & 591 \\
\hline $\mathrm{ZrO}_{2}$ & 0.000 & 0.320 & 555 \\
\hline $\mathrm{B}_{2} \mathrm{O}_{3}{ }^{*} \mathrm{Li}_{2} \mathrm{O}$ & 0.000 & 0.074 & 3662 \\
\hline $\mathrm{Others}^{\dagger}$ & 0.000 & 0.600 & 445 \\
\hline
\end{tabular}

